\title{
A Set-Up of 7 Laser Triangulation Sensors and a Draw-Wire Sensor for Measuring Relative Displacement of a Piston Rod Mechanical Lead-Through Transmission in an Offshore Wave Energy Converter on the Ocean Floor
}

\author{
E. Strömstedt, O. Svensson, and M. Leijon \\ The Swedish Centre for Renewable Electric Energy Conversion, Division for Electricity, Department of Engineering Sciences, \\ Uppsala University, Box 534, 75121 Uppsala, Sweden \\ Correspondence should be addressed to E. Strömstedt, erland.stromstedt@gmail.com
}

Received 26 July 2011; Accepted 4 September 2011

Academic Editors: G. Namkoong and S. Rehman

Copyright (C) 2012 E. Strömstedt et al. This is an open access article distributed under the Creative Commons Attribution License, which permits unrestricted use, distribution, and reproduction in any medium, provided the original work is properly cited.

\begin{abstract}
A concept for offshore wave energy conversion is being developed at the Swedish Centre for Renewable Electric Energy Conversion at Uppsala University in Sweden. The wave energy converter (WEC) in focus contains a piston rod mechanical lead-through transmission for transmitting the absorbed mechanical wave energy through the generator capsule wall while preventing seawater from entering the capsule. A set-up of 7 laser triangulation sensors has been installed inside the WEC to measure relative displacement of the piston rod and its corresponding seal housing. A draw-wire sensor has also been set up to measure translator position and the axial displacement of the piston rod. The paper gives a brief introduction to the Lysekil research site, the WEC concept, and the direct drive of WEC prototype L2. A model of operation for the piston rod mechanical lead-through transmission is given. The paper presents sensor choice, configuration, adaptation, mounting, and measurement system calibration along with a description of the data acquisition system. Results from $60 \mathrm{~s}$ measurements of nominal operation two months apart with centered moving averages are presented. Uncertainty and error estimations with statistical analyses and signal-to-noise ratios are presented. Conclusions are drawn on the relative motions of the piston rod and the seal housing under normal operating conditions, and an assessment of the applicability of the measurement system is made.
\end{abstract}

\section{Introduction}

A number of wave energy converter (WEC) technologies are in development around the world [1-6]. The Swedish Centre for Renewable Electric Energy Conversion at Uppsala University, Sweden, has for the past decade been working on a WEC characterized as point absorber with a surfacefloating buoy and an encapsulated permanent magnet linear generator bolted to a foundation on the ocean floor. The WEC is suitable for offshore installation, outside of breakwater areas, for absorbing wave power primarily in heave mode at depths ranging from 20 to $100 \mathrm{~m}$.

The maintenance and life time of a WEC can be far more important to the economical viability than the conversion efficiency, especially if it is an offshore installation requiring divers and large sea vessels $[7,8]$. The WEC design at Uppsala
University constitutes a straightforward design based on a direct drive with few mechanical parts. Few mechanical parts promote a longer maintenance-free life time. All parts of the wave energy conversion system are sheltered at the seabed, except for the relatively cheap and robust surface floating buoy. Large surface forces from big waves thus only act on the buoy and affect the rest of the WEC by pulling the buoy line (or connection line).

The direct drive excludes expensive, complicated, and sensitive gear boxes and hydraulics. Instead, the buoy line is connected to a piston rod mechanical-lead through transmission which transmits the absorbed mechanical energy through the capsule wall and into the generator while preventing seawater from entering the capsule. If seawater enters the capsule, the generator will start to corrode and reduce the life time of the WEC. 


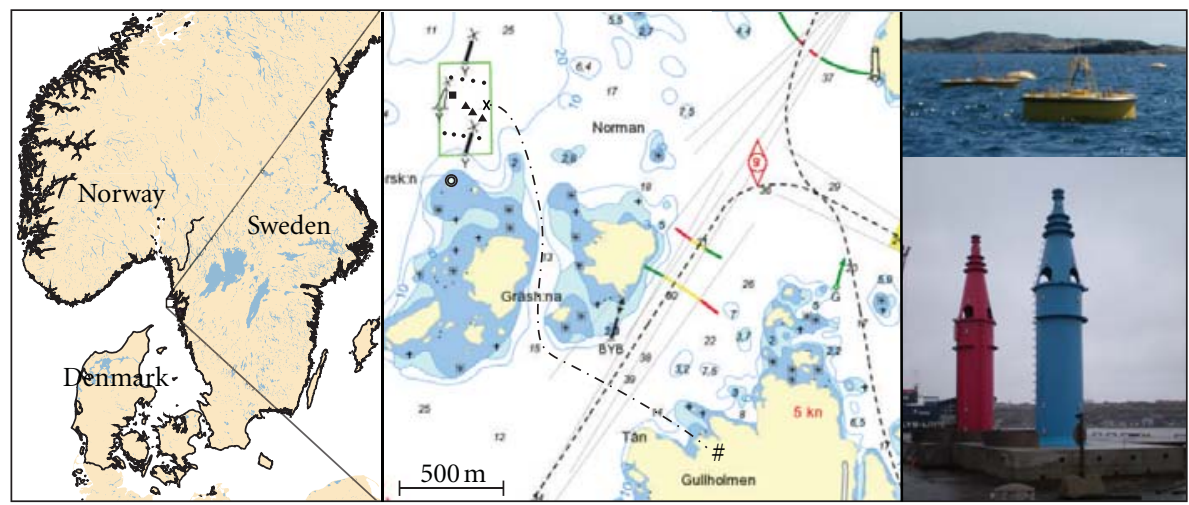

I Research site markers (x3)

- WEC prototypes $(\mathrm{x} 3)$

$x$ Underwater substation

- Wave measurement buoy
- Biology buoys (x8)

- Observation tower

-- - Sea cables to shore

\# Measuring station (cabin)

Figure 1: (Left) A map of the geographical location of the LRS. (Middle) A sea chart pointing out the operational installations at the time of the experiment. (Lower right) WEC L2 (blue/right); L3 (red/left). (Top right) Two wave energy converter buoys on site with the buoy of $\mathrm{L} 2$ in the foreground. Two biology buoys are in the far background.

During operation an offshore WEC has to sustain millions of cyclical sequences of varying static, dynamic, and potentially very high mechanical loads in the harsh environment at sea. In this study a set-up of 7 laser triangulation sensors has been installed inside one of the WECs to measure relative displacement of the piston rod and its corresponding seal housing in the mechanical lead-through. A drawwire sensor has also been installed to measure the axial displacement of the piston rod and the vertical translator position. The aim of the displacement measurements is to investigate the behavior and performance of the piston rod mechanical lead-through transmission and to enable evaluation of the successive wear on the guide elements and sealing components housed inside the seal housing.

This paper presents (i) a brief presentation of the Lysekil research site, (ii) the WEC concept and the WEC fitted with the sensors (prototype L2), (iii) a theoretical model of the piston rod mechanical lead-through transmission in L2, (iv) the choice of sensors for the measurement task, (v) the geometrical set-up of the 7 laser triangulation sensors and the draw-wire sensor, (vi) the theory for measuring relative displacement rather than absolute position, (vii) the experimental configuration, adaptation, mounting, and system calibration, (viii) the data acquisition system, (ix) results from two different measurement periods 2,5 months apart with centered moving averages, $(\mathrm{x})$ a statistical analysis of uncertainties, error estimations, and signal-to-noise ratios, (xi) an in-depth discussion, and finally (xii) conclusions drawn from the experiment.

\section{Background}

2.1. The Lysekil Research Site. The most relevant environment and interesting circumstance to investigate WEC technology is through field studies of full-scale WEC prototypes in operation at sea. In order to perform full-scale testing a full-scale wave power park has been developed at the Lysekil research site (LRS). The LRS is situated $3 \mathrm{~km}$ offshore about $100 \mathrm{~km}$ north of Gothenburg on the west coast of Sweden; see Figure 1. It has a water depth of $25 \mathrm{~m}$ and a flat sandy bottom. More information on the LRS can be found in [9].

On May 15, 2009 the first wave power park at the LRS was put into operation. During the experiment in 2009 the park contained 3 generations of WEC prototypes, $\mathrm{L} 1, \mathrm{~L} 2$, and L3. The WECs are rated at $10 \mathrm{~kW}$ and have 3 -phase permanent magnet linear generators producing AC with varying amplitudes and frequencies depending on the energy period of the ocean waves. 3 WEC buoys with different geometrical configuration were evaluated. An offshore underwater substation acting as a junction for collecting the AC power from the 3 WECs was also launched. The substation rectifies the power, collects it on a common DC-bus, inverts the aggregated DC to a common AC at grid frequency $(50 \mathrm{~Hz})$, and transforms it to high voltage $(1 \mathrm{kV})$. A $2 \mathrm{~km}$ long high voltage sea cable relays the generated power from the offshore underwater substation to the onshore measuring station, where resistive loads convert the electric energy into heat.

One of the introduced features of L2, L3, and the offshore underwater substation was the installation of a multitude of sensors and a data acquisition system for evaluation of individual mechanical subsystems, the operating conditions, and the overall WEC performance [10]. The LRS also includes a number of so-called biology buoys (up to 30) that are directly connected to concrete foundations for studying bio fouling and environmental impact [11]. In order to relate experimental results to prevailing sea states a wave measurement buoy (Waverider buoy) has been installed measuring significant wave height and wave energy period [12]. The LRS also contains an observation tower with a controllable network camera for studying buoy movements 
[13]. Figure 1 displays the installations at the LRS at the start of the wave park experiment on the 15th of May, with L2 at coordinates Lat $58^{\circ} 11^{\prime} 42.48^{\prime \prime}$ and Long $11^{\circ} 22^{\prime} 26.40^{\prime \prime}$. The experiment progressed until the 23rd of September 2009.

A wave energy system with arrays of smaller WECs has the advantage of power generation redundancy compared to a system based on a large single WEC. If one of the smaller WECs malfunctions and requires maintenance, it can be removed without a significant impact on the overall power generation. Studies have shown that the ratio between the power absorbed by an array and $N$ times the power absorbed by an isolated WEC, among other things, supports the idea of using arrays of smaller devices $[14,15]$.

From the wave park experiments at the LRS in 2009 papers have been published on the offshore underwater substation [16], the electrical system and control of the wave power park [17-19], the control and measurement system used in the offshore underwater substation [20], and on temperature measurements inside WEC L2 and the offshore underwater substation [21], among others.

2.2. WEC Concept and Prototype L2. The first WEC prototype, L1, has been described in earlier papers [9, 22]. After the launch of L1, in March of 2006, the WEC design was overhauled. Several mechanical parts were changed and improved in L2, but no conceptual changes were introduced and no changes were made to influence generator rating parameters. The electromagnetic characteristics, geometry, and efficiency of the permanent magnet linear generator have been presented in earlier papers $[23,24]$. The same WEC configuration was kept in L2 in order to evaluate the performance of the electrical and mechanical subsystems present in both of the first two prototypes. Prototype L3, on the other hand, introduced mechanical upgrades.

A mechanical description of L2 will now set the context for the study in focus in this article. The chosen buoy for L2 was a flat puck-shaped cylindrical steel structure weighing 2 tons with an outside diameter of $3 \mathrm{~m}$ and a height of $1.2 \mathrm{~m}$; see buoy in foreground of top right-hand image in Figure 1. L2 is $9.35 \mathrm{~m}$ high from the top rim of the funnel to the bottom of the foundation; see blue WEC to the lower right of Figure 1 and CAD assembly model in Figure 2. Starting from the bottom, the WEC consists of a flat cubic steel-reinforced concrete foundation, with dimensions $5.4 \times 5.4 \times 0.7 \mathrm{~m}$, weighing 49 tons. It has 8 cut outs on each side to improve the artificial reef effect $[11,25]$. The foundation has a $12 \mathrm{~cm}$ high and $5 \mathrm{~mm}$ thick steel frame underneath all around the periphery. It creates suction towards the seabed to add to the gravitational pull.

The outer structure consists of a capsule and a superstructure. The capsule surrounding the L2-generator is $5.15 \mathrm{~m}$ high. It has an outside diameter of $1.566 \mathrm{~m}$ and a wall thickness of $8 \mathrm{~mm}$. The capsule is $0.20 \mathrm{~m}$ higher than the capsule on L1. The extra space appears between the upper end stop and the capsule top plate to make room for the set-up of the 7 laser triangulation sensors. The change in capsule height has no major influence on the operational performance of L2 compared to L1. The cone-shaped steel superstructure is $3.2 \mathrm{~m}$ high with a $10 \mathrm{~mm}$ wall thickness.
The superstructure is flooded with seawater since it is open at the top through the funnel and on four orthogonal sides just above the capsule top plate.

Inside the capsule, 4 vertical square beams make up the corner pillars of the so-called inner framework for the linear generator. The corner pillars are connected by cross bars on three levels. The inner framework is bolted to the capsule bottom plate and to the upper end stop. The 4 stator sections are $1264 \mathrm{~mm}$ long and $400 \mathrm{~mm}$ wide. Each stator section is supported by 4 stator beams on the backside and bolted to the outside of the corner pillars. The $1.867 \mathrm{~m}$ long 4-sided translator is fitted with Nd-Fe-B permanent magnets and reciprocates inside the framework. 8 retracting tensile springs accelerate the downward motion to increase the output power. The translator is guided by 24 cup spring suspended track rollers. They are mounted on 3 levels, in 4 orthogonal directions, and bear off against 8 roller conveyors of hardened steel mounted on the inside of the 4 corner pillars. The track rollers maintain the air gap between the translator and stator at $2.5 \mathrm{~mm}$ by having a higher cup spring force gradient compared to the magnetic force gradient.

The buoy line is adjusted to a length that generally puts the translator in the middle between the two end stops at calm seas. However, the LRS is subjected to a tidal difference of about $30-40 \mathrm{~cm}$ which alters this position from time to time. The reciprocal motion of the translator is repeated for each wave with a typical wave energy period of 2-12 s.

The stroke length of the generator is a design parameter which is chosen in regard to the wave height responsible for contributing to the largest part of the yearly power generation, that is, the highest level of electric energy conversion. For the LRS this corresponds to a significant wave height of $2 \mathrm{~m}$, an energy period of $6 \mathrm{~s}$, and an energy flux of $5-10 \mathrm{~kW} / \mathrm{m}$ [26]. The generator in L2 has therefore been designed with a maximum translator stroke length of $2.210 \mathrm{~m}$ between the end stops. The so-called free stroke length occurs between the end stop compression springs. In L2 the free stroke length is $1.797 \mathrm{~m}$.

Different power take-off (PTO) systems exist in wave power technology [27]. In WEC L2 the PTO consists of the buoy and a direct drive connected to the translator. The direct drive consists of the buoy line and the piston rod mechanical lead-through transmission. The buoy is the first moving part and the translator is the last moving part in the WEC. After that the electrical system takes over beginning with the stator windings and ending with the onshore measuring station (or if applicable a connection to the grid).
2.3. The Reason for Using a Tilting Piston Rod. When the buoy moves around on the ocean surface, the buoy line assumes an elevation angle toward the vertical axis. The azimuth angle depends on the lateral position of the buoy which in turn depends on the direction of the incoming waves, the wind, and the sea currents. When the axially loaded buoy line slides through the funnel at the top of the superstructure, friction occurs at the interface. The contact results in the funnel absorbing a side force. A lateral 


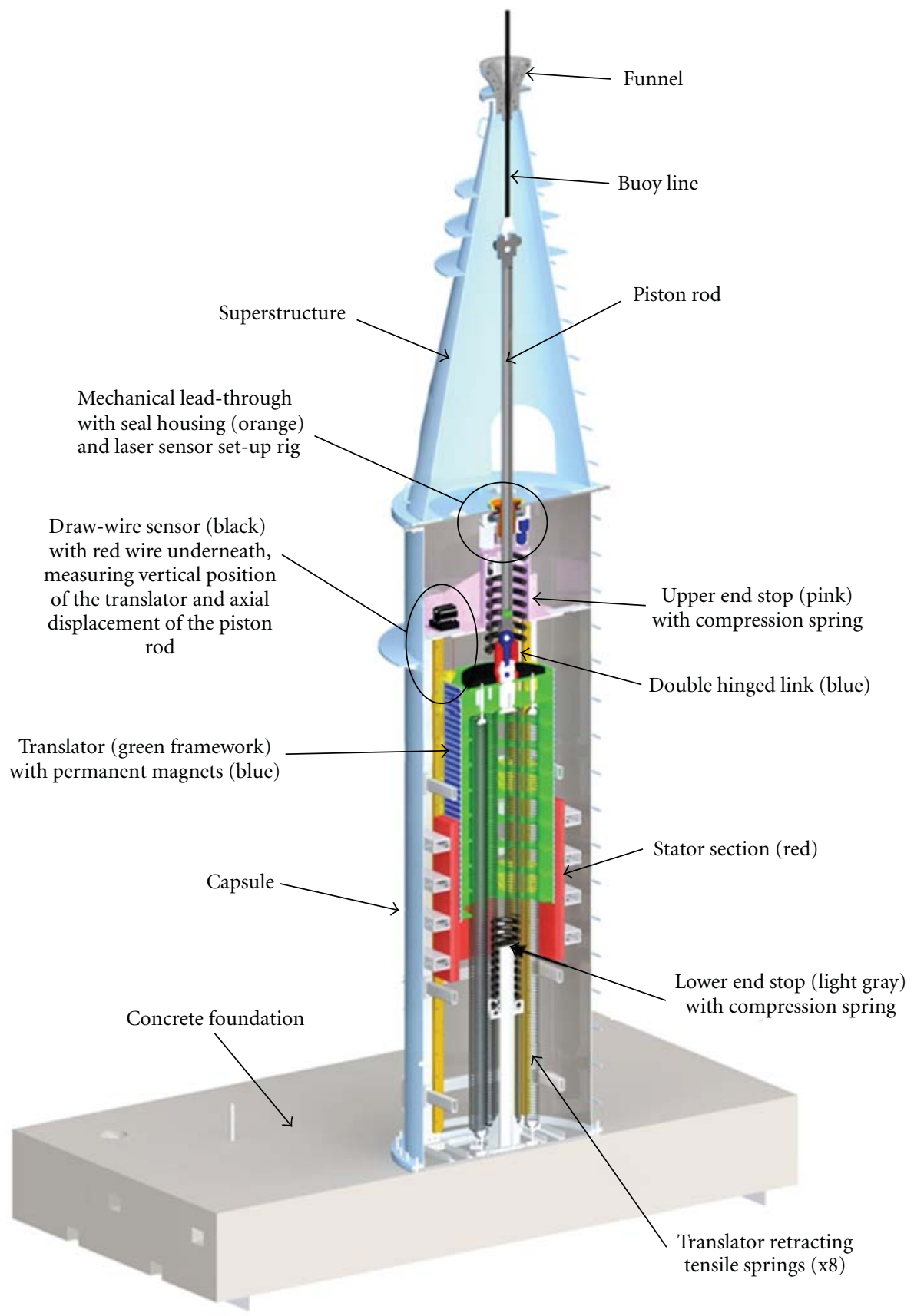

FIGURE 2: Cross-sectional view of the CAD assembly model of WEC L2 according to scale, with major functional parts indicated and relevant displacement sensors encircled.

displacement of the buoy line and funnel follows due to the elastic bending of the superstructure and capsule.

The magnitude of the lateral displacement depends on the stiffness of the steel structures, from the top through the superstructure and capsule all the way down to the concrete foundation. The mechanical moment acting on the outer steel structure is counteracted by the gravitational pull of the steel-reinforced concrete foundation. In order not to bend the piston rod the transmission is designed to allow the piston rod to tilt. The tilting of the piston rod requires a flexible mechanical lead-through or the side forces and bending moment will be too high for the components in the mechanical lead-through to handle.

\section{Theory}

3.1. Model of the Piston Rod Mechanical Lead-Through Transmission in L2. In order to explain the purpose of the set-up of the 7 laser triangulation sensors and the drawwire sensor we need to take a closer look at the measured 


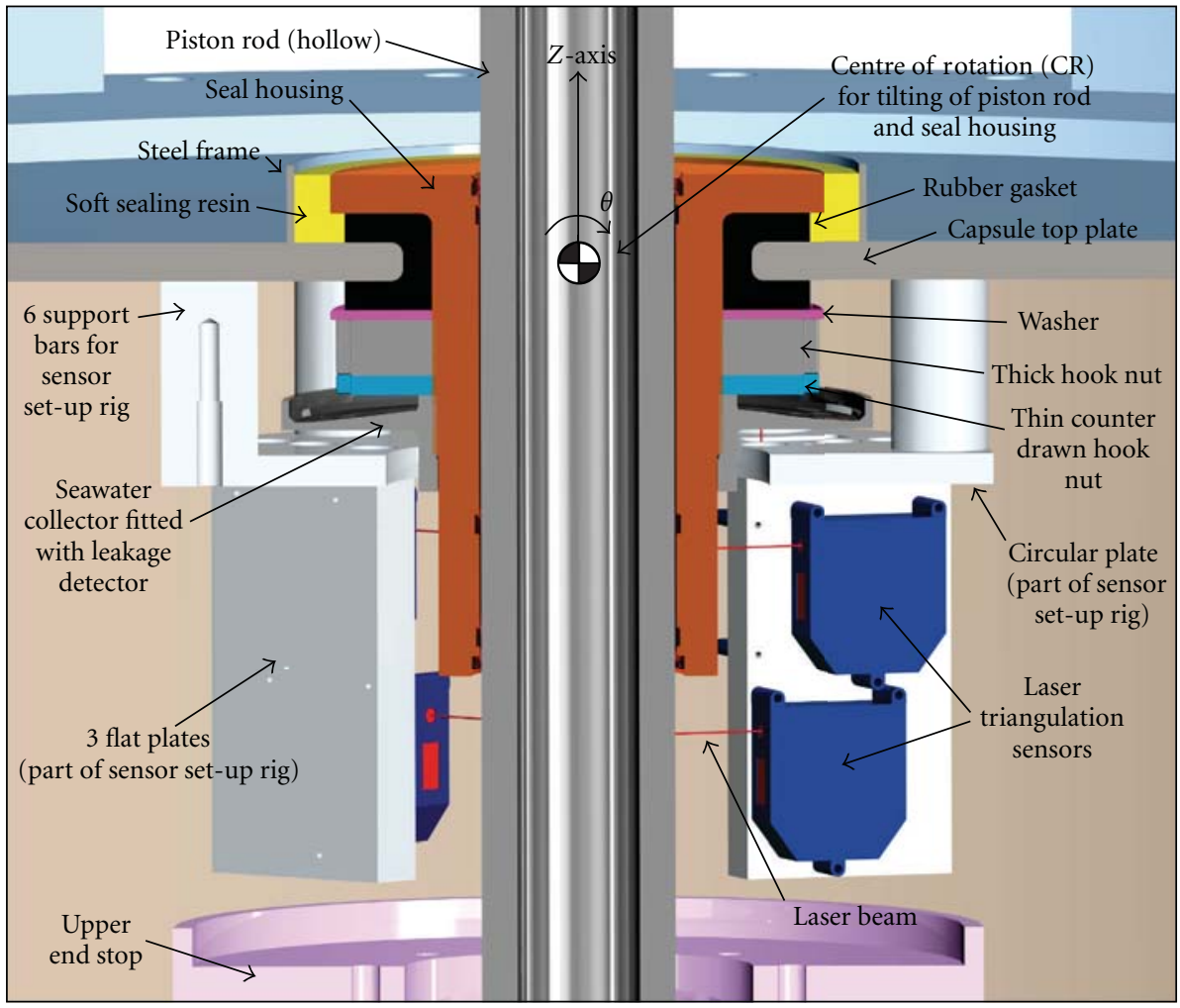

Figure 3: Cross-sectional view of the CAD assembly model of the piston rod mechanical lead-through with the surrounding laser triangulation sensor set-up.

objects and their function in L2. Figures 3, 4, and 5 present cross-sectional views of the CAD assembly according to scale showing different parts of the piston rod mechanical lead-through transmission. Figure 3 presents the measured objects and other components in the mechanical leadthrough at the capsule top plate. It also displays the sensor set-up rig for the 7 laser triangulation sensors.

The $15 \mathrm{~m}$ long buoy line is the first section of the direct drive. It consists of a so-called Steel wire Powerplast [28], which is guided through a funnel at the top of the generator superstructure. Underneath the funnel the buoy line connects to a piston rod which reciprocates with the same stroke length as the translator. The piston rod transmits the absorbed mechanical energy from the buoy line to the translator through the seal housing in the mechanical leadthrough at the centre of the capsule top plate. The seal housing has several inside grooves for fitting guide elements and sealing components, which seal against the reciprocating piston rod to prevent seawater from entering the generator capsule.

The seal housing is clamped onto a C-shaped rubber gasket enabling flexibility. The gasket is clamped between the seal housing flange and a joint containing a washer and two hook nuts. The hook nuts are screwed onto M150 threads on the outside middle section of the seal housing. The clamped rubber gasket constitutes a static seal to prevent seawater from entering the capsule between the seal housing and the capsule top plate. A soft sealing resin has been added in a gorge outside the rubber gasket to improve the seal. A seawater collector is screwed on to the outside threads of the seal housing, underneath the hook nuts, to collect any leakage through the sealing resin and rubber gasket for detection with a water leakage detector.

The first measured object is the piston rod. It is a $2935 \mathrm{~mm}$ long hollow bar made of duplex stainless steel, denoted by SAF 2205 (or EN 1.4462). It has an outer diameter of $99.94 \mathrm{~mm}$. The outer surface is roller burnished. The other measured object is the seal housing. It is a $260 \mathrm{~mm}$ long hollow cylinder with a $255 \mathrm{~mm}$ wide and $20 \mathrm{~mm}$ thick top flange; see Figures 2 and 3. The seal housing is made of austenitic stainless steel, denoted by 254 SMO (or EN 1.4547). The lower part of the outside surface facing the laser triangulation sensors has an outer diameter of $143.97 \mathrm{~mm}$.

Each end of the piston rod is fitted with a clevis in the same material as the piston rod. The upper rod end clevis is connected to the buoy line. A thimble is fitted into the clevis and a clevis pin fitted through the thimble secured by two nuts and a cotter; see Figure 4. To avoid bimetal corrosion the galvanized thimble is separated from the stainless steel clevis by two thin fiber-reinforced polymer composite plates, one on each side of the thimble, and a sleeve on the clevis pin (not visible in Figure 4). The upper rod end clevis joint in Figure 4 has one degree of rotational freedom around the axis of the clevis pin. The rotation is not required for the function of the transmission. 


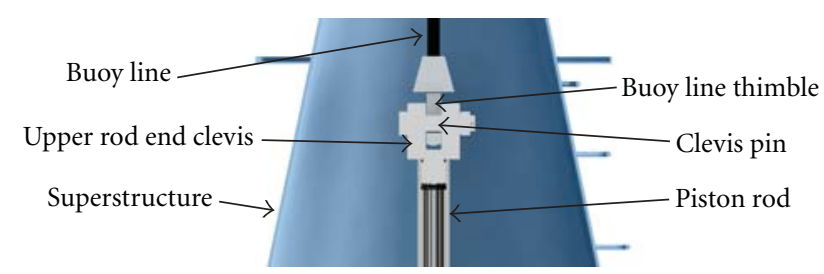

FIGURE 4: Cross-sectional view of the CAD assembly model of the upper part of the piston rod mechanical lead-through transmission, where the buoy line connects to the piston rod.

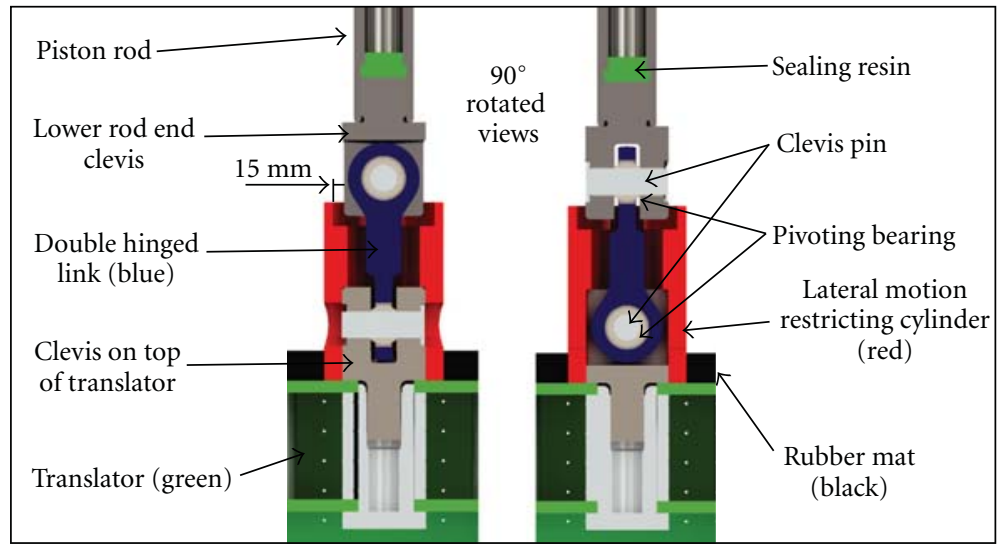

FIGURE 5: Two cross-sectional views of the CAD assembly model of the double-hinged link and the clevis joints on top of the translator with surrounding lateral motion restricting cylinder.

Inside the capsule the piston rod connects to the third section of the direct drive, a $0.3 \mathrm{~m}$ long double-hinged link with pivoting bearings at each end with a $90^{\circ}$ parting; see Figure 5. The piston rod mechanical lead-through transmission ends by the double-hinged link being attached to a clevis on top of the translator. The pivoting bearings enable three rotational degrees of freedom and allow the double-hinged link to tilt up to $3.2^{\circ}$ in any required direction around the vertical axis.

A so-called lateral motion restricting cylinder is mounted around the double-hinged link. It restricts the lateral displacement of the lower rod end clevis to a maximum of $15 \mathrm{~mm}$; see Figure 5. During normal operation the lower rod end clevis is not supposed to come into contact with the lateral motion restricting cylinder, which acts as a security measure to prevent the piston rod from sliding too far down into the seal housing in case there is a slack in the buoy line.

During operation the upper rod end will follow the oscillating lateral displacement of the funnel. The piston rod will thus tilt back and forth, with oscillating elevation angle (or tilt angle) $\theta$ towards the $z$-axis, and with a certain azimuth angle corresponding to the lateral surface position of the buoy. The $z$-axis in Figure 3 constitutes the centre axis of the laser triangulation sensor set-up. It is normal to the $20 \mathrm{~mm}$ thick capsule top plate. The position of the centre of rotation (CR) for the tilting of the piston rod becomes the intersectional point between the piston rod centre axis and the middle layer of the capsule top plate. This position coincides with the centre position in the rubber gasket. In theory, the double hinged link enables CR to be maintained in its position throughout an entire wave period by allowing the lower end of the piston rod to swing out sideways in the opposite direction compared to the funnel.

The theoretical model of the piston rod mechanical leadthrough transmission is based on the elastic rubber gasket enabling the seal housing to follow the tilting motion of the piston rod. As a result there will only be a small increase in the side forces that act on the guide elements and sealing components during the peak amplitudes of the wave period. This enables lower friction and wear. In theory, the piston rod and seal housing tilt together in any azimuth angle (or lateral direction). The transmission is generally not designed to operate with the piston rod forcing the seal housing to translate sideways. However, it should be able to handle small translations and vibrations due to the configuration of the rubber gasket. In the later case, however, elevated side forces may increase the friction. The progressive wear on the guide elements result in an increasing relative tilt angle between the centre axis of the piston rod and seal housing. This in turn reduces the clearance gap at the edges of the seal housing.

The sealing constitutes a crucial function for the WEC with a potentially large impact on life time and the need of maintenance. The motion of the piston rod and the seal housing needs to be measured in order to evaluate the successive wear on the sealing components and their sustainability during operation.

3.2. Choice of Noncontact Displacement Sensor. In order to perform the measurement task some kind is of displacement 
sensor or sensors need to be installed in close vicinity of the mechanical lead-through. There are many considerations involved in choosing sensing technology $[29,30]$. The choice of displacement sensor in this case depends on mounting possibilities, spatial limitations inside the WEC, conditions and sensitivity of the measured surfaces, measurement environment, working distance, required measurement range, resolution, and accuracy.

Displacement sensors can be classified into four categories, active contact, active noncontact, passive contact, and passive noncontact. Commonly active and passive sensors are classified due to their need (or lack of) external active circuitry to produce the electrical output signal from the sensor [29]. They can however also be classified according to whether they passively rely on some kind of energetic excitation from the measured objects, or if they are in need of active excitation form the sensor or any other added external source. The former distinction is not so interesting since most sensor and measurement systems, including this one, need active signal amplifiers close by the sensor.

Classifying sensors into contact or noncontact is very straightforward. Any sensor statically mounted on the measured object or in continuous or intermittent dynamic contact with the measured object is a contact sensor. A noncontact sensor is not in any contact with the measured object at any time during the measurement.

In making the choice we consider the following. The measured objects do not emit any energy possible to detect with a passive noncontact sensor. It is also very difficult to mount anything inside the piston rod, such as magnets, which could be sensed by a passive sensor. The rollerburnished piston rod is touch-sensitive and risk damage or wear if operating in contact with an actuator or a touch probe. Wear on the piston rod or touch probe would inflict unknown and critical errors in the measurements as well as disturb the experimental results. Thus the first conclusion regarding the choice of sensor is that it needs to be of an active noncontact type.

The sensor is meant to be rigidly set up and mounted close to the mechanical lead-through. It will need to be able to measure for several months, or possibly years, isolated in the WEC $25 \mathrm{~m}$ below the ocean surface. For that purpose the sensor needs to be robust and reliable with good repeatability without being inflicted by hysteresis. If several sensors are needed for the measurement task, the size of the sensor has to be small enough for many of them to be mounted at different angles and viewpoints in the limited space around the mechanical lead-through. The total available space for the sensor set-up is $33 \mathrm{~cm}$ vertically between the capsule top plate and the upper end stop and approximately $65 \mathrm{~cm}$ in radial direction between the measured objects and the capsule wall. This also sets the limits for the working distance.

A suitable measuring range was estimated by structure mechanical FEM simulations carried out on the WEC's outer steel structure and inner framework using CAD/FEM software called Pro/Engineer and Pro/Mechanica Wildfire 5.0. A side force was applied to the funnel based on measurements made in experiments with WEC L1. An axial force transducer, model U2B $200 \mathrm{kN}$ from HBM, had been used to measure the axial force in the buoy line [9]. The lateral (or horizontal) displacement of the target surfaces was estimated to be in the order of millimeters, but not to exceed $\pm 10 \mathrm{~mm}$. A suitable measuring range would therefore be $20 \mathrm{~mm}$ if the sensors were to measure from the side in a horizontal plane. This measuring range also takes the uncertainty of all misalignments during WEC assembly into account.

The sensor resolution will need to be around the level of microns $(\mu \mathrm{m})$ in order to detect the small changes in relative displacement between the measured objects that occurs due to initial play and successive wear on the guide elements and sealing components. A high measuring frequency would increase the precision and give enough samples to enable adequate filtering in order to increase the signal-to-noise ratio. A low nonlinearity is also required for good accuracy, especially when small relative displacements are measured.

Many different active noncontact displacement sensor technologies have been reviewed and some of the references are given in [31-53]. The choice was made to use 7 laser triangulation sensors from Micro-Epsilon, called optoNCDT 1700-20 [54, 55]. Table 1 displays some of the technical data for the optoNCDT 1700-20. The optoNCDT 170020 measures linear displacement by method of active laser triangulation through noncontact sensing of the diffuse reflection from a projected visible laser point (spot) on a target surface [56].

The principle of active laser triangulation is illustrated in Figure 6. A laser beam is focused by a transmitting lens onto a target surface. On the surface we can observe a small light spot. A portion of the diffuse reflection from the laser spot is collected by a receiving lens, or multi-lens optics, and then focused as an image on a detector. A chargecoupled device (CCD) array is a favored detector for its high sensitivity, dynamic range, and inherent geometric stability [57]. It returns the peak value, which is the true centre of the laser spot. In contrast, a position sensing detector (PSD) returns the centre of beam spot distribution with a slight variation from the true peak value. The detector is tilted to maintain the so-called Scheimpflug condition, see (1), and thereby allowing good focusing for the whole depth of the measuring range [58]:

$$
R=R_{0}-\frac{A \cdot \Delta x}{(\Delta x \cdot \cos \alpha)+(B \cdot \sin \alpha)}
$$

with $R_{0}$ representing the midrange reference distance, $R$ the measured distance, $\Delta x$ the detected image shift on the CCD array, $\alpha$ the angle of triangulation for the reference distance, $B$ the focal length, and $A$ the distance between the principal point in the receiving lens and the laser spot for the reference distance on the CCD array.

In the case of optoNCDT 1700-20 the laser beam originates from a semiconductor diode laser, having the advantages of a simple structure, small volume, lightweight, high efficiency, and low price [59]. The diode laser produces a very small spot size which is good for precision. The diffuse reflection from the laser spot is focused by a multi-lens system to a CCD array with real-time surface compensation (RTSC). The RTSC technology regulates the 


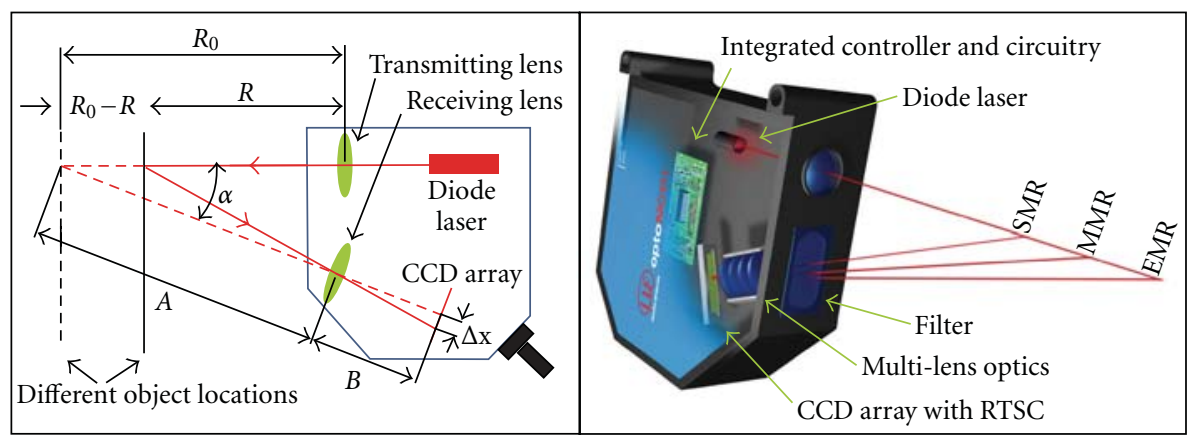

FIGURE 6: (Left) An illustration of the method of active laser triangulation. (Right) The optoNCDT 1700-20 with major functional parts and measuring range indicated.

amount of light produced in real-time to optically match the reflective characteristics of the target surface, from almost total absorption to almost total reflection. This is required since we are measuring on highly reflective stainless steel surfaces.

The chosen sensor is compact with overall casing dimensions $75 \times 97 \times 30 \mathrm{~mm}$. It will be mounted with the target surfaces at midrange (MMR) distance; see Figure 6. In that way the measurement amplitude of $\pm 10 \mathrm{~mm}$ will be able to pick up movements in both directions regardless of which azimuth direction the measured objects are tilting in.

Active laser triangulation and how it is applied inside the optoNCDT 1700-20 will not be further described in this paper. It can be found in literature, for instance, $[54,55]$. The sensor is perceived to be reliable, accurate enough, and in all important aspects a good match for the measurement task. Anything similar to the sensor set-up and the relative displacement measurements carried out in-situ on two measured objects in relative motion, such as the piston rod and the seal housing, inside an offshore WEC in operation have not been found in literature and have, to the authors' knowledge, not been performed earlier [60].

3.3. Geometrical Set-Up of Laser Sensors. The 7 laser triangulation sensors measure linear distance from 7 stationary viewpoints on a rigid sensor set-up rig towards the target surfaces of the moving piston rod and seal housing. The circular geometry and multiple degrees of freedom of motion of the measured objects require measurement by a set-up of at least 3 laser sensors per measured object. 3 laser sensors enable the description of 3 degrees of freedom. The degrees of freedom of interest are the tilt angle (or elevation angle), the azimuth angle of tilting, and the possible horizontal translation in the mentioned azimuth direction.

The 7 laser triangulation sensors, denoted by piston rod laser sensor (PRLS) 1-3 and seal housing laser sensor (SHLS) 1-4, are rigidly mounted onto 3 rectangular plates at specific relative geometrical positions. The geometrical set-up of the laser beams is illustrated in the schematic sketches of Figure 7. PRLSs 1-3 measure toward the piston rod surface from three different directions with $120^{\circ}$ angular parting and with $6 \mathrm{~mm}$ relative separation between each sensor in the $z$-axis direction. SHLSs $1-3$ measure towards
TABLE 1: Table of technical data for optoNCDT 1700-20.

\begin{tabular}{|c|c|}
\hline Measuring range & $20 \mathrm{~mm}$ \\
\hline $\begin{array}{l}\text { Start of measuring range } \\
(\mathrm{SMR})\end{array}$ & $40 \mathrm{~mm}$ \\
\hline Midrange (MMR) & $50 \mathrm{~mm}$ \\
\hline $\begin{array}{l}\text { End of measuring range } \\
\text { (EMR) }\end{array}$ & $60 \mathrm{~mm}$ \\
\hline Linearity (of FSO) & $\begin{array}{l}<0.015 \% \text { FSO }(3 \mu \mathrm{m} \text { or } \pm 1.5 \mu \mathrm{m}) \\
\text { from factory calibration protocol } \\
\text { (Catalogue value: }<0.08 \% \mathrm{FSO})\end{array}$ \\
\hline Resolution & $1.5 \mu \mathrm{m}$ (at $2.5 \mathrm{kHz}$ without averaging) \\
\hline Measuring rate & $312.5 \mathrm{~Hz}-2.5 \mathrm{kHz}$ (adjustable) \\
\hline Light source & $\begin{array}{l}\text { Semiconductor laser }<1 \mathrm{~mW}, 670 \mathrm{~nm} \\
\text { (red) }\end{array}$ \\
\hline \multicolumn{2}{|l|}{ Spot diameter } \\
\hline SMR & $320 \mu \mathrm{m}$ \\
\hline MMR & $45 \mu \mathrm{m}$ \\
\hline EMR & $320 \mu \mathrm{m}$ \\
\hline Operation temperature & $0 \cdots+50^{\circ} \mathrm{C}$ \\
\hline Temperature stability & $0.01 \% \mathrm{FSO} /{ }^{\circ} \mathrm{C}$ \\
\hline Output & $0-10 \mathrm{~V}, 4-20 \mathrm{~mA}$ or RS 422 \\
\hline Power supply & $24 \mathrm{VDC}, \max 150 \mathrm{~mA}$ \\
\hline $\begin{array}{l}\text { Permissible ambient light } \\
\text { (at } 2.5 \mathrm{kHz} \text { ) }\end{array}$ & $10000 \operatorname{lux}$ \\
\hline Laser safety class & Class 2 acc. DIN EN 60825-1: 2001-11 \\
\hline EMC & EN 61000-6-3, EN 61000-6-2 \\
\hline Housing material & Zinc die casting \\
\hline Sensor cable length & $0.25 \mathrm{~m}$, option: $3 \mathrm{~m}$ or $10 \mathrm{~m}$ \\
\hline Protection class & IP 65 \\
\hline Vibration & $2 \mathrm{~g} / 20 \cdots 500 \mathrm{~Hz}$ \\
\hline Mechanical shock & $15 \mathrm{~g} / 6 \mathrm{~ms}$ \\
\hline Weight (with $0.25 \mathrm{~m}$ cable) & $550 \mathrm{~g}$ \\
\hline
\end{tabular}

the seal housing surface from the same three directions and with $6 \mathrm{~mm}$ relative separation between each sensor in $z$-axis direction. The reason for the particular sensor partitioning has to do with the mathematical model and set of equations for describing the motion, which is outside of the scope of this article. 

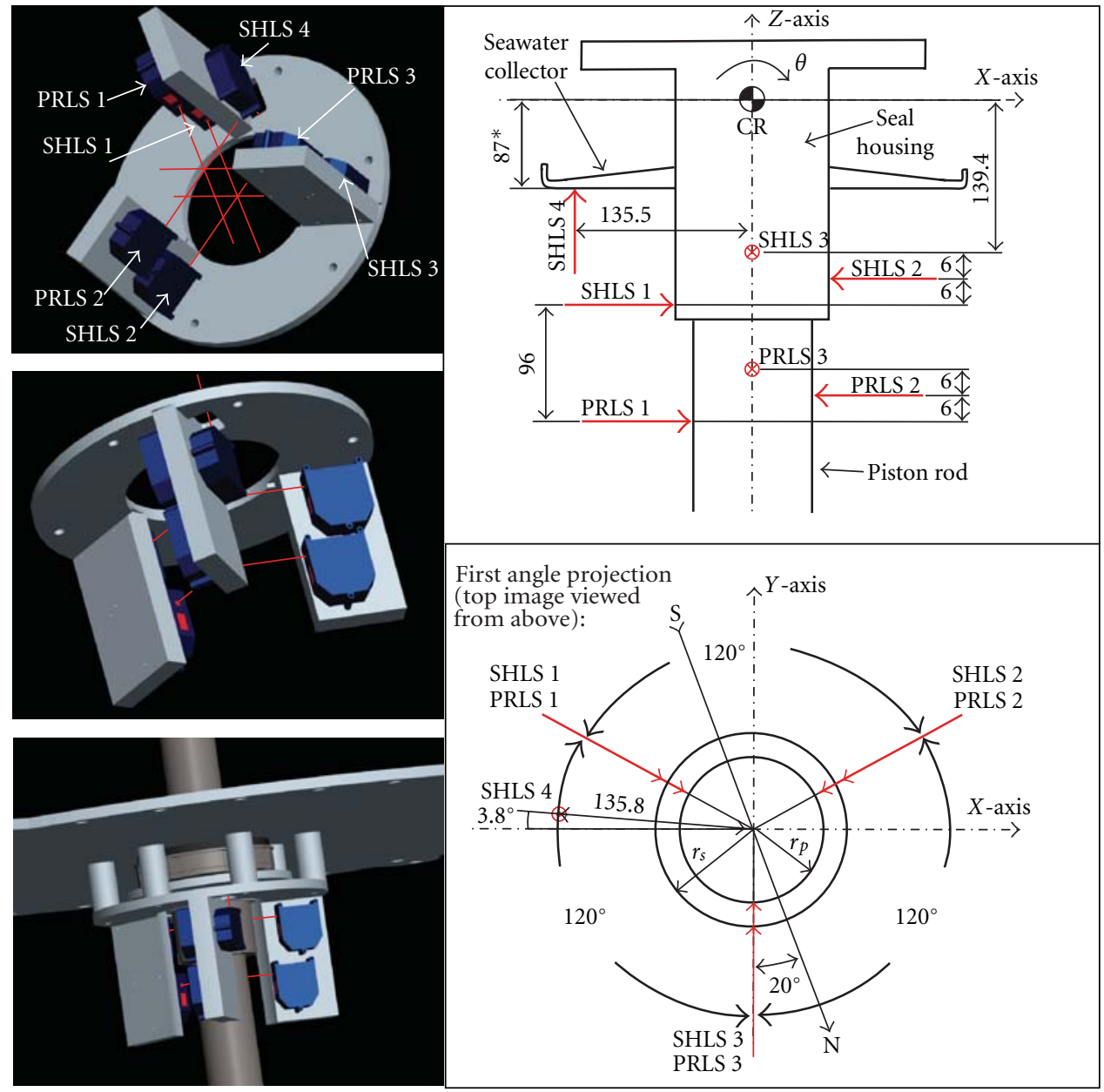

$\begin{array}{lcl}\mathrm{N}=\text { North } & r_{p}=\text { Piston rod radius } & \text { CR: centre of } \theta \text {-rotation Sensors mounted at MMR ( } 50 \text { mm to target surface), } \\ \mathrm{S}=\text { South } & r_{s}=\text { Seal housing radius } & * \text { depending in part on the compression of the rubber gasket, see Figure } 3\end{array}$

FIgURE 7: (Top left) CAD assembly view of the laser sensor set-up rig with sensor positions indicated. (Middle left) CAD assembly view of the laser sensor set-up rig from another view point. (Bottom left) CAD assembly view of the laser sensor set-up rig mounted underneath the capsule top plate surrounding the piston rod mechanical lead-through. (Top right) Illustration of the relative positions of the laser beams in the $x$ - $z$-plane. (Bottom right) Illustration of the relative positions of the laser beams in the $x$-y-plane.

The sensors are grouped in pairs on each plate, the lower one measuring on the piston rod and the upper one measuring on the seal housing. Since the seal housing has a larger diameter, SHLSs 1-3 are positioned a bit further out in the perimeter compared to PRLS 1-3. The initial distance between the sensors and their respective target surfaces should match the midrange distance $(50 \mathrm{~mm})$ of the laser triangulation sensors. The physical mounting of the sensors and the sensor set-up rig is further described in Section 4.5.

The 7th sensor in the set-up is the 4th sensor measuring on the seal housing. It is denoted by SHLS 4 and is mounted on the offside of the rectangular plate with PRLS 1 and SHLS 1. SHLS 4 measures the linear distance towards the bottom surface of the seawater collector in the $z$-axis direction. A water leakage indicator is connected to the seawater collector in order to detect and indicate if leakage occurs through the static seal of the sealing resin and rubber gasket. Since SHLS 4 measures in the $z$-axis direction, not covered by SHLS
$1-3$, it is possible to pick up seal housing translation in the $z$ axis direction, which might occur due to the elasticity of the rubber gasket.

The capsule top plate is considered to behave like a rigid body. FEM simulations show that bending of the capsule and superstructure during operation, due to side forces absorbed at the funnel, will not deform the top plate. The stress and strain levels acting on the $20 \mathrm{~mm}$ thick top plate are very small and will not affect the sensor set-up rig or the measurements. In other words, there will not be any relative displacement between the $z$-axis of the sensor set-up rig and the corresponding centre axis of the capsule top plate. The top plate and the sensor set-up rig constitute a rigid body and consequently the mentioned axes are in constant alignment.

The horizontal $x$-y-plane of the sensor set-up rig is parallel to and at level with the capsule top plate middle layer; see Figures 3 and 7. The centre of $\theta$-rotation (CR) for the piston rod and the seal housing is located at the same level 
in the centre of the opening of the capsule top plate. In other words, the given coordinate system of the sensor set-up rig in Figure 7 serves the purpose of relating the laser sensors to each other and to CR. The north and south point of the compass is indicated with an estimated tolerance of $\pm 5^{\circ}$ in the lower right image of Figure 7.

The displacements are measured by the sensors in common mode. Depending on the relative position of the sensors the output will reflect the motion relative to the top plate. The common mode measurement is enabled by the rigid body of the laser sensor set-up rig and the rigid connection between the set-up rig and the rigid capsule top plate.

3.4. Geometrical Set-Up of Draw-Wire Sensor. The axial displacement of the reciprocating piston rod, that is, the translation in the direction of the piston rod centre axis, is not measured by the laser triangulation sensors. It is obtained, although not with the same precision and accuracy, with an additional draw-wire sensor. The draw-wire sensor is a standard wire sensor of model WDS-3000-P115-SA-PE from Micro-Epsilon [61]. The sensor has a measuring range of $3000 \mathrm{~mm}$ and a nonlinearity of $\pm 0.1 \%$ of FSO. The analogue voltage output is used. A "quasi-infinite" resolution is achieved with a so-called hybrid potentiometer. The rest of the technical data can be found in the instructional manual for the draw-wire sensor [62].

The geometrical set-up of the draw-wire sensor inside the WEC is presented in Figure 8. The piston rod operates with an oscillating tilt angle. Meanwhile the draw-wire sensor measures the vertical position of the translator. In the process it measures the piston rod axial translation in the direction of the momentary tilt angle. Since the maximum tilt angle of the piston rod is small, up to an approximate maximum of $1^{\circ}$, there is practically no difference between the vertical displacement of the translator and the axial displacement of the piston rod.

The results in this paper are given as "piston rod outside length" in mm. "Piston rod outside length" refers to the part of the piston rod sticking out, above the seal housing, and into the seawater. Output from the laser triangulation sensors can be correlated with output from the draw-wire sensor in order to explain and evaluate the relative displacement between the piston rod and the seal housing in the piston rod mechanical lead-through transmission.

3.5. Relative Displacement versus Absolute Position. The main purpose of the laser sensor measurements is to measure the tilt angle between the piston rod and the seal housing. The tilt angle results from the initial play between, and successive wear on, the components which separates the two objects in the dynamic sealing system. The individual tilt angles of the two measured objects are calculated from the measured linear distance between each sensor and its respective target surface. A set of equations takes the object geometries and the geometrical set-up of sensors into account to determine the motion of the measured objects.
The accuracy of the laser sensor measurement system needs to be good in order for it to be possible to evaluate the small variations in tilt angle between the piston rod and the seal housing. Two different methods can be distinguished by the different ways of measuring the displacements of the individual measured objects, that is, by measuring relative displacement or absolute position.

Measuring the absolute position of the measured objects with regard to a fixed coordinate system inside the WEC also involves establishing the absolute position of the sensors within that coordinate system as well as the direction of the vector of each laser beam, as mentioned by Chen et al. [38]. It is very difficult to position multiple sensors to equal the precision and accuracy of one sensor, without accumulated errors in the measurements. It is of course possible to measure the exact position of the sensors and the beams after they have been mounted and fixed on the setup rig. This may be done with a coordinate measurement machine (CMM). Even if this is done, the method results in a more complex mathematical model. It would also increase the magnitude of inaccuracy due to the increased number of error sources accompanied with all the steps in establishing the positions and beam vectors.

The other method involves measuring and comparing relative displacements, or change in measured distance, as measured by the sensors and to calculate a relative tilt angle from that. Measuring relative displacement of the objects only involves establishing a starting point in time and then comparing the change in measured distances for each sensor. This is possible to do regardless of what the distance is between the sensor and the target surface. The ocean waves move the measured objects cyclically back and forth with a varying amplitude and time period. It is therefore only the change in position during that cycle that matter in describing the relative displacement between the piston rod and the seal housing. Any relation to a coordinate system is irrelevant except for the spatial relation between the sensors; that is, sensors measuring on the piston rod needs to be fixed in relation to the sensors measuring on the seal housing. The individual tilt angles can thus be analyzed and compared without a common reference point. As long as the piston rod and the seal housing are measured by a set-up of sensors that measure from a stable and stationary set-up rig, a relative displacement measuring method will become the most accurate due to the lower number of accumulated errors involved.

Other aspects favor the method of comparing relative displacement. For instance, the mechanical lead-through is not by design required to be positioned in the exact centre of the capsule top plate. In fact, the double-hinged link and the rubber gasket allow lateral misalignments due to accumulated tolerances or misalignments in WEC assembly. Establishing the absolute position of the overall mechanical lead-though is therefore not specifically interesting for the main purpose of the laser sensor measurements. The important aspect is to investigate the relative cyclical motion of, and between, the two measured objects. 

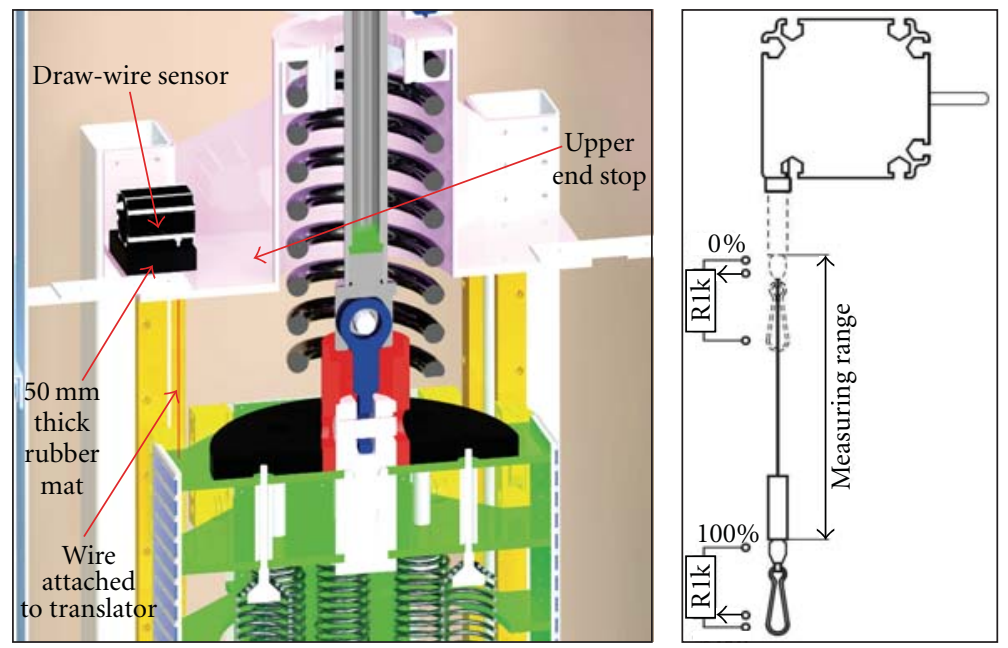

FIGURE 8: (Left) CAD assembly model of the set-up of the draw-wire sensor inside WEC L2 for measuring vertical translator position and reciprocal piston rod axial displacement. (Right) A sketch of the draw-wire sensor measurement principle [62].
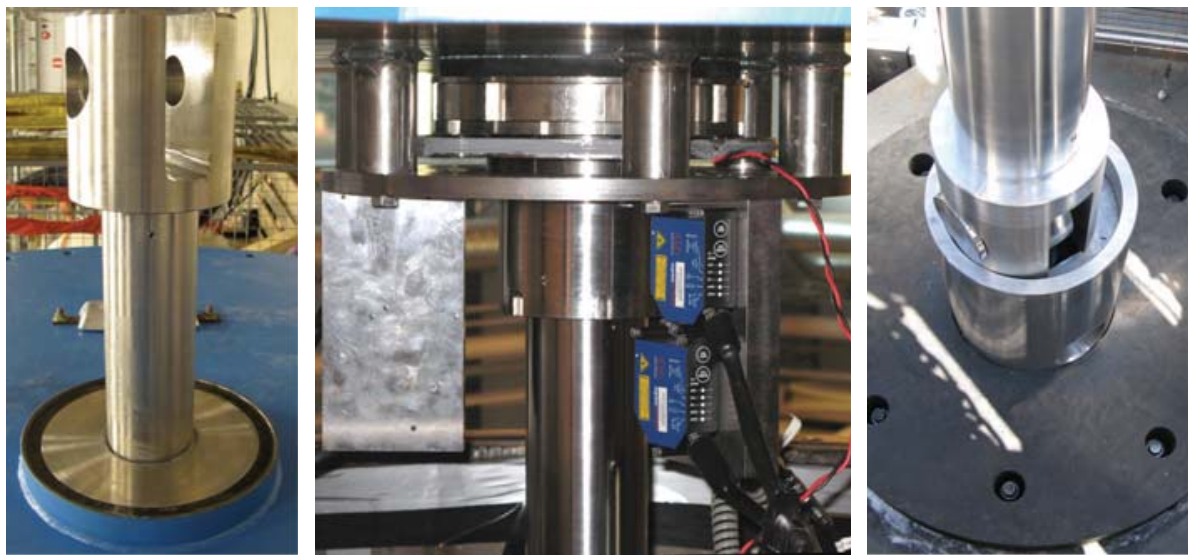

FIGURE 9: The piston rod mechanical lead-through in WEC L2. (Left) Piston rod sticking out through the seal housing with upper rod end clevis on top. (Middle) The mechanical lead-through and the laser sensor set-up rig underneath the top plate. (Right) Lower piston rod end clevis connected to the double-hinged link with lateral motion restricting cylinder on top of the translator.

\section{Experiment}

4.1. The Measured Objects. The constructed piston rod mechanical lead-through transmission in WEC L2 is presented in Figure 9. The left image shows part of the upper rod end, with the clevis, sticking out through the seal housing. The blue-colored top plate is mounted to the capsule. The middle image shows the mechanical lead-through and the sensor set-up underneath the capsule top plate just before the top plate is lowered down the last $30-40 \mathrm{~cm}$ in order to close the capsule. The piston rod has moved half way through the seal housing at this point and the laser sensor set-up rig surrounds the mechanical lead-through. The right image shows the lower piston rod end with the clevis mounted to the double-hinged link. The double-hinged link is in turn mounted to the clevis on top of the translator (not visible in Figure 9). The lateral motion restricting cylinder surrounds the double hinged link. At the upper right-hand corner of the right image the wire from the draw-wire sensor is seen attached to the top of the translator.

4.2. Target Surfaces for Laser Sensors. Some of the factors that play a significant role in the output quality from laser triangulation sensors can be found in $[57,63,64]$. Target surface reflectance, shape changes, curvatures, and change in color and temperature can influence the output of a laser triangulation sensor. The output can also be influenced by speckle noise (or surface noise), due to the roughness and crystal structure of the target surface. All the stated disturbances can be corrected for, except for the speckle noise which only can be reduced. Speckle constitutes a fundamental limit to the accuracy of the laser triangulation sensor [57].

Speckle noise arises when the laser beam bounces off of a target surface that is rough compared to the wavelength 


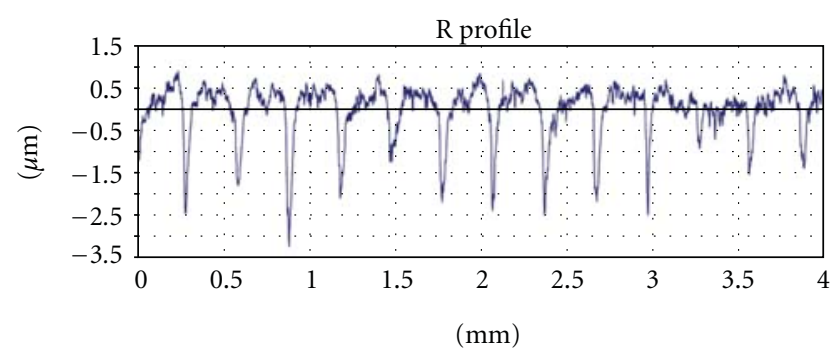

FIGURE 10: Surface roughness profile for the roller-burnished piston rod surface facing PRLS 1-3.

of the laser. The surface roughness introduces random variations in the optical path lengths, causing a random interference pattern throughout space and at the sensor detector. The result is a noise component that affects the pulse detection, causing range errors even from a flat target [64]. Uniform reflectance variations over the entire laser spot can be handled by sensor technology like the RTSC technology, described in Section 3.2. Speckle, on the other hand, occurs due to variations in the reflectance inside the laser spot. Sensors using an oval laser spot are known to reduce speckle, such as the optoNCDT 1700LL [54]. However, it is estimated that the circular spot from the standard optoNCDT 1700 will perform well enough on curved surfaces with respect to precision and accuracy due to a smaller spot size. A larger oval spot will deform on a curved surface, which may reduce accuracy.

The target surface on the piston rod consists of a rollerburnished duplex stainless steel with a suitable surface profile for reducing friction and wear against components in the dynamic sealing system. The piston rod surface has been measured with a surface roughness tester, SJ-400, from Mitutoyo $[65,66]$. The roughness parameters for the piston rod, averaged over 7 measurements, showed $R_{a}=0.36 \mu \mathrm{m}, R_{z}$ $=2.74 \mu \mathrm{m}$, and $R_{t}=3.46 \mu \mathrm{m}$. The roller-burnished surface profile also showed an average $R_{\mathrm{mr}}=69.2 \%$ at cutting depth $1.2 \mu \mathrm{m}$, with a standard deviation of $15 \%$. The target surface facing the sensors on the seal housing consists of a grinded austenitic stainless steel. The roughness parameters have been measured with the same surface roughness tester. An average of 2 measurements showed $R_{a}=0.80 \mu \mathrm{m}, R_{z}=$ $5.8 \mu \mathrm{m}$, and $R_{t}=7.0 \mu \mathrm{m}$. $R_{\mathrm{mr}}$ was approximately between 40 and $50 \%$ at cutting depth $2.4 \mu \mathrm{m}$. Surface roughness profiles of the piston rod and seal housing, according to ISO 1997 with a Gauss filter, can be seen in Figures 10 and 11.

According to Micro-Epsilon, traversing a surface roughness of $5 \mu \mathrm{m}$ or more leads to an apparent distance change due to speckle noise. However, these apparent distance changes can be reduced by averaging [55]. As seen in Figures 10 and 11 , the surface roughness of the target surfaces is mostly below the limit. However, the reflectance of the crystal structure in a metal such as stainless steel will still cause some unknown amount of speckle noise. In comparison to white noise, speckle noise is not random but a property of the chosen laser and the target surface. Stainless steel has a reflectance index of approximately $60-65 \%$, depending on

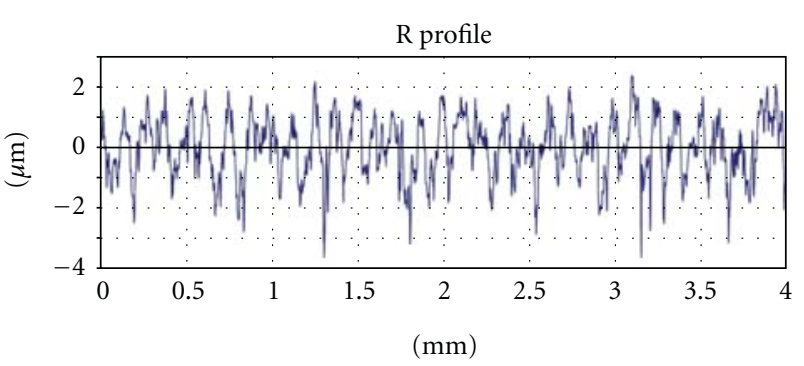

FIGURE 11: Surface roughness profile for the grinded seal housing surface facing SHLS 1-3.

crystal structure, for light at $690 \mathrm{~nm}$ wavelength [67]. This is slightly reduced by the amount of oxide and, in the case of the piston rod, by the lubrication grease required for reducing friction against the dynamic sealing system. In any case, the target surfaces have a rather high scattering performance. It is therefore suitable to measure distance by detecting diffuse reflection with a sensor emitting a laser beam at a normal incidence angle [59].

The target surfaces have no macroscopic shape changes causing occlusion. However, the curvatures relating to the radiuses of the target surfaces need to be evaluated in order to establish if they have an influence on the measurements. An apparent distance change may occur if the angle between an incident laser beam and the target surface normal, at the point where the laser spots hit the surface, increases too much. This is further discussed in Section 6.3.

\subsection{The Measurement Environment and Adaptation of Sen-} sors. The robustness of the sensors is an important factor, since the sensors need to be resistant to influence from environmental noise inside the WEC. As far as the sensor goes, robustness needs to be considered for both the sensor hardware circuitry and the measurand. Two sources of signal interference within the WEC are the strong permanent magnets, made of $\mathrm{Nd}-\mathrm{Fe}-\mathrm{B}$, on the translator and the $\mathrm{AC}$ currents in the stator windings. These emit strong magnetic and electromagnetic fields. Laser light is not sensitive to these fields, but the sensor circuitry and the data acquisition system could be subjected to noise. In our case, the sensors, the cables, and all parts of the measurement technology inside the WEC are screened and grounded to the inside of the capsule steel wall. The steel wall is in contact with the outside seawater at various unpainted spots. These spots would be open to corrosion in the seawater if they were not protected by sacrificial $\mathrm{Zn}$-anodes. The sensor itself is grounded and screened by a zinc die cast casing.

The laser sensors are fitted with optical interference filters for suppressing light from other sources, which can be a problem when measuring on shiny surfaces. However, the sensors have been mounted in such directions that they do not interfere with each other; see Section 3.2. There are no sources of light inside the capsule besides the laser sensors; so ambient light will not be a source of interference. The basic ambient temperature inside the WEC changes slowly with the seasons from about $+3^{\circ} \mathrm{C}$ in winter time to approximately 


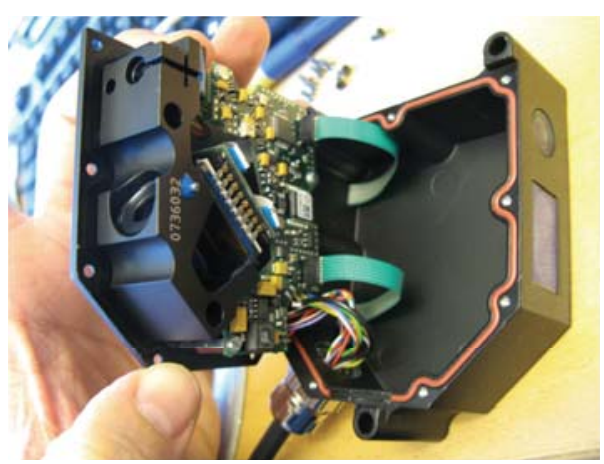

(a)

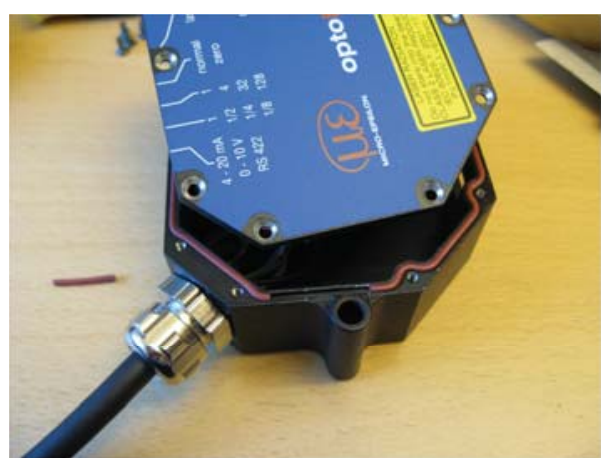

(b)

FIGURE 12: (a) The sensor, with all components mounted to the back plate. (b) The casing with the cut open o-ring sealing creating a balance duct for decompression during descent to the ocean floor.

$+20^{\circ} \mathrm{C}$ at summer time, due to the shallow waters. Studies show that heat emitted from the generator can increase the ambient temperature about $1{ }^{\circ} \mathrm{C}$ due to a successive change in sea state from $5 \mathrm{~kW} / \mathrm{m}$ to $20 \mathrm{~kW} / \mathrm{m}$ over a time of 35 hours [21]. The relative humidity is assumed to be very high and could possibly reach $100 \%$, with condensation as a result. Possible water leakage may also occur through any of the openings into the capsule. However, the entire capsule would have to fill up before the sensors are flooded since they are mounted right underneath the capsule top plate.

The WEC is assembled at atmospheric pressure, that is, 1 bar of absolute pressure, inside an assembly hall. After assembly it is depressurized to 0.7 bar absolute pressure and then repressurized back to 1 bar with nitrogen gas $\left(\mathrm{N}_{2}\right)$. This is repeated 3 times over. The oxygen concentration is thereby reduced from $21 \%$ to approximately $7 \%$. During launch the capsule is continuously pressurized with nitrogen gas as the WEC is lowered down to the seabed to equal the outside seawater pressure at the capsule bottom plate. The nitrogen gas is supplied through a hose from pressure tanks on the surface vessel. The hose is connected to a pressure valve on the capsule. When the WEC reaches the seabed at $25 \mathrm{~m}$ depth, the inside pressure has increased to 3.5 bars equaling the outside seawater pressure at the level of the capsule bottom plate. The oxygen concentration is thereby reduced to $2 \%$. The capsule is pressurized during descent to improve the structural mechanical properties of the capsule in order to reduce the required wall thickness. 5 meters above the capsule bottom plate the mechanical lead-through is exposed to 0.5 bar inside overpressure compared to the pressure of the outside seawater. When launch is completed, the valve is closed and locked by the divers before the hose is detached and pulled up to the surface.

The components inside the laser sensors are all mounted to a plate, the so-called back plate, before the sensor is factory calibrated by the manufacturer. After factory calibration, a casing is mounted to the back plate. An o-ring is fitted between the casing and the back plate to keep the sensor air tight and sealed off; see Figure 12. According to the manufacturer the casing would not be able to withstand the increased pressure during launch, but the electronic components would. The sensor casing was therefore opened and approximately $10 \mathrm{~mm}$ of the o-ring was cut off to create a compensating balance duct. The duct enables decompression of the sensor casing during launch.

The o-ring is cut opened at the side of the sensor which will be facing downwards in the sensor set-up. The duct will allow a higher relative humidity to spread inside the sensor, but gravity will prevent inside condensation from accumulating. Gravity will also prevent seawater from leaking into the casing through the duct, unless of course the whole generator capsule is flooded. Condensation will not influence the measurements, according to the manufacturer, unless it occurs on the optical parts. If that happens, the laser will not be able to measure correctly and the error value of $10.2 \mathrm{~V}$ will be sent as output signal and easily distinguished from the real measurement values. The inside absolute pressure of 3.5 bars and the concentration of $98 \%$ nitrogen gas and $2 \%$ oxygen gas will not have any effect on the accuracy at all. The pressure level is simply too low to constitute a problem. The reduction in oxygen is performed in order to reduce corrosion inside the generator capsule.

Other sources of disturbance in the measurement environment can be mechanical vibrations. Inside the WEC, vibrations can occur when the 24 track rollers guide the translator against the 8 roller conveyors on the inner framework or when the buoy line slides against the funnel. Generator cogging could also be a possible source of mechanical vibrations. Shock occurs when the translator slams into the end stops. The sources of vibration inside the WEC are closer and more directly connected to the measured objects than to the laser sensor set-up rig. It is an advantage that the set-up rig is positioned far away from the sources. The amplitudes will be reduced and absorbed by other parts of the WEC before they reach the set-up rig. If necessary spectral analysis and filtering of the sensor output will enable common mode suppression of vibrations, since the sensors are all mounted to the same structure and would vibrate together, if at all.

The draw-wire sensor casing is drilled with the same consideration to open up for decompression, according to the advice from the manufacturer Micro-Epsilon. The 


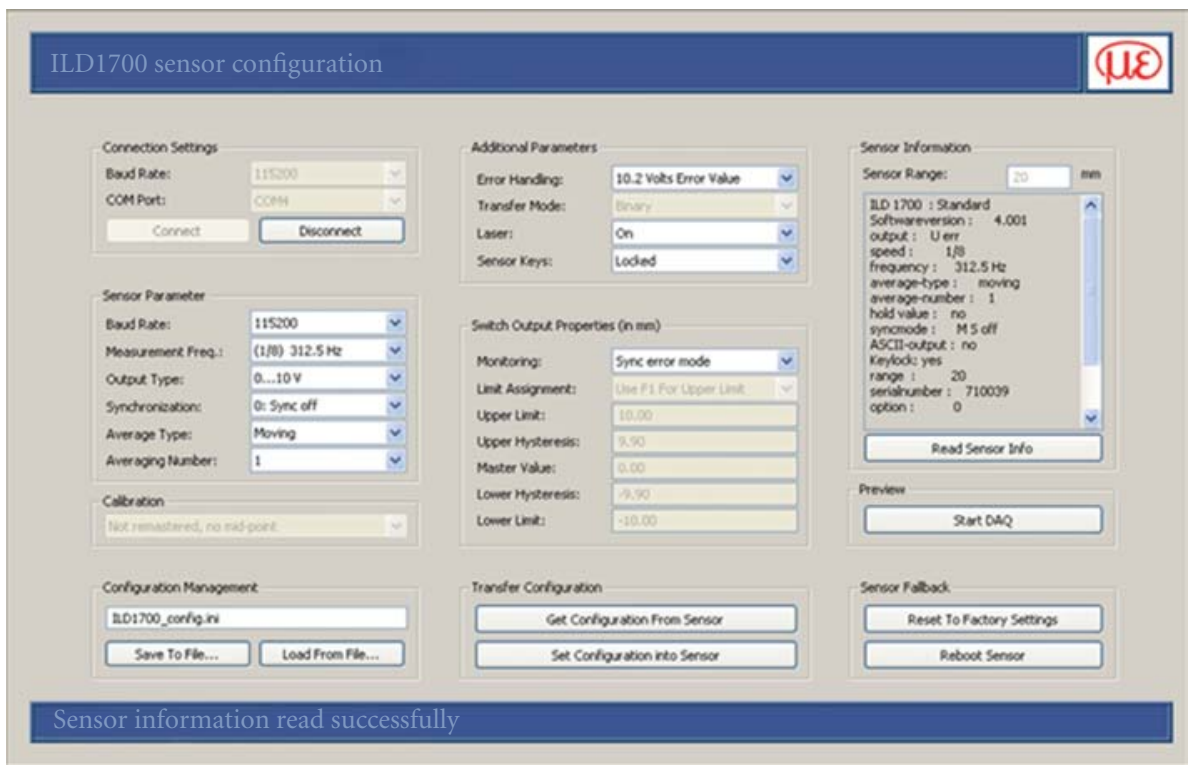

FIGURE 13: The graphical user interface for sensor configuration showing the sensor settings for the WEC experiment.

possibility of reaching $100 \%$ humidity or condensation will not affect the performance or accuracy of the draw-wire sensor. It may however shorten the life time due to inside corrosion. Micro-Epsilon has stated that the same kind of draw-wire sensor has been successfully used in the harsh aquatic environment on Öresund's bridge between Sweden and Denmark. Water was entering the sensor casing during long durations without any influence on the measurements.

4.4. Laser Sensor Configuration. The graphical user interface of the laser sensor configuration software and the chosen settings for the sensors during the WEC experiment are displayed in Figure 13. Considerations are made with regard to the general application, the target surfaces, the measurement environment, and the data acquisition system.

One of the most important settings is the choice of sensor sampling frequency (or measurement frequency). It is possible to reduce speckle noise, from measuring on shiny and polished stainless steel surfaces, by setting a longer sensor exposure time. The controller in the sensor regulates exposure time depending on choice of measurement frequency. To achieve a longer exposure time the measurement frequency has to be reduced. Since the motions of the measured objects are slow and depending on the ocean waves, the sensors can be configured to sample at the lowest frequency of $312.5 \mathrm{~Hz}$. In this way the exposure time is maximized and speckle noise reduced without the risk of under sampling.

The output type is set to analogue voltage between 0 and $10 \mathrm{~V}$. The setting of baud rate is not relevant for sensors operating with analogue voltage output. Synchronization is switched off, since we are not using a synchronization card. Average type is set to "Moving" with averaging number of "1" to return the raw data without averaging. The scientific value of analyzing the output supersedes the interest of receiving a smooth signal with eliminated spikes. Filtering can always be performed in post-measurement data processing.

The laser sensors are configured to be online as soon as power is supplied. All sensor keys are locked so that no one accidently changes the settings by touching the keys on the sensors. The switch output properties are set to "Sync error mode" to return the error voltage value of $10.2 \mathrm{~V}$ whenever the measurement range is exceeded, if the measured target surfaces become immeasurable or if the optical parts get compromised. In case of an exceeded measurement range, the hysteresis limits are set to enable the return from the error voltage value to a valid measurement value at $9.90 \mathrm{~mm}$ $(9.95 \mathrm{~V})$ and $-9.90 \mathrm{~mm}(0.05 \mathrm{~V})$, respectively.

4.5. Laser Sensor Set-Up Rig and Mounting of Sensors. The laser sensor set-up rig consists of three thick rectangular steel plates for the mounting of the sensors and a flat circular steel sheave for connecting the plates into one rigid structure. The structure is mounted towards 6 steel support bars underneath the top plate; see Figure 3 and the middle image in Figure 9. Figure 14 displays the different parts and assembly steps for the set-up rig and the mounting of the laser sensors.

The more precise the measurement needs to be, the more precise the laser sensor fixturing is required [68]. Sensor holding structures that bridge all sides of the target and uses stiff supports on all sides are preferred. In our case, the rigidly assembled laser sensor set-up rig surrounds the measured objects inside the WEC. The three rectangular plates, displayed in Figures 14(a) and 14(b), are very precisely milled, drilled, and threaded. A very accurate coordinate table was used for milling and positioning the holes so that the relative positions between each sensor would be as exact as possible. The laser sensors are very rigidly mounted to each plate, using M4-bolts. The 7th laser sensor is mounted on the 


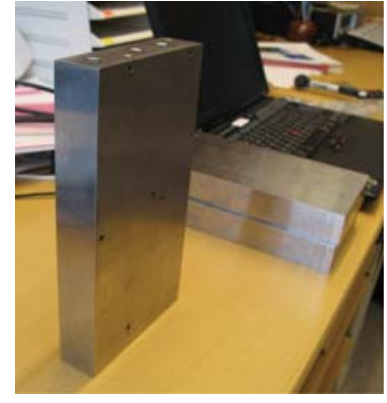

(a)

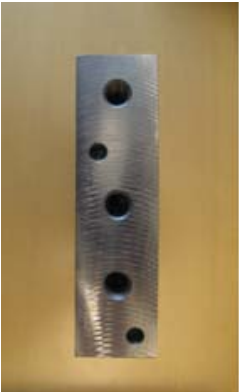

(b)

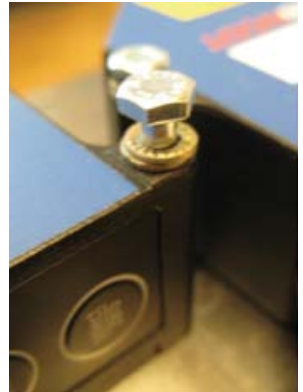

(c)

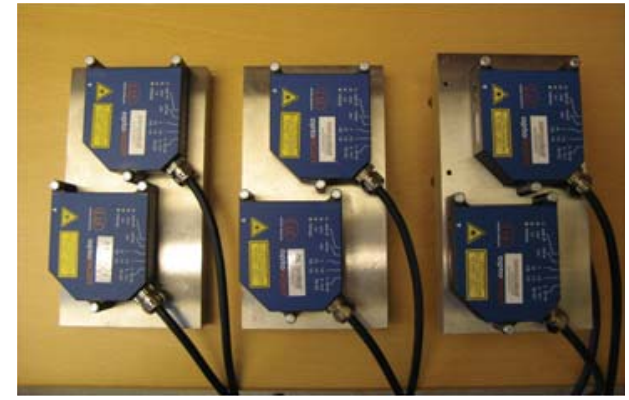

(d)

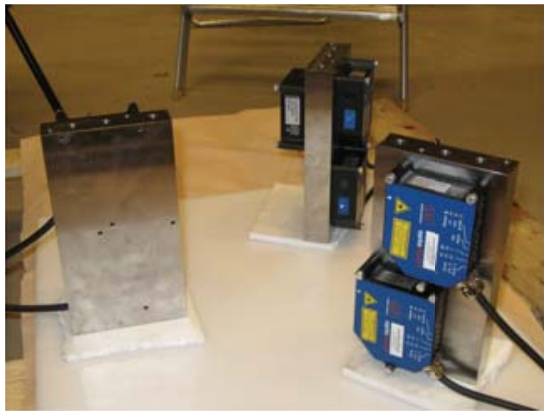

(e)

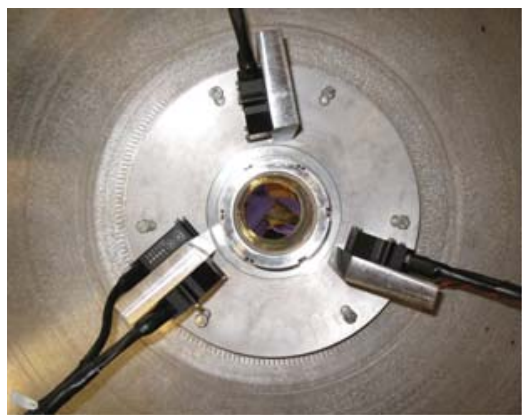

(h)

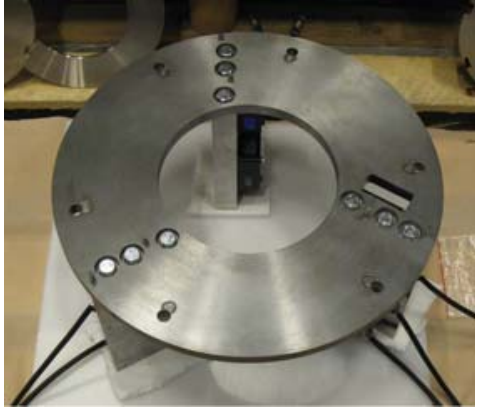

(f)

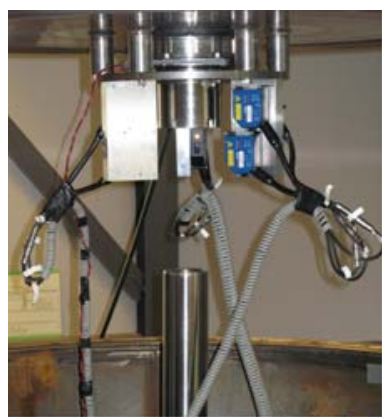

(i)

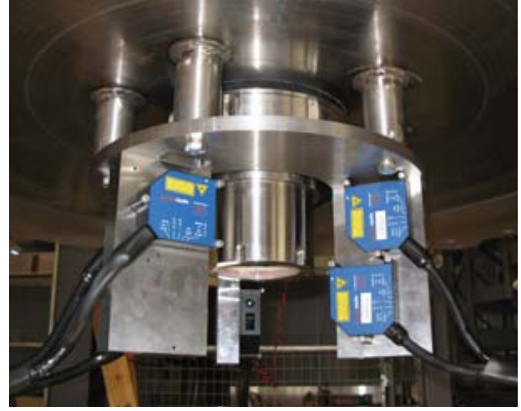

(g)

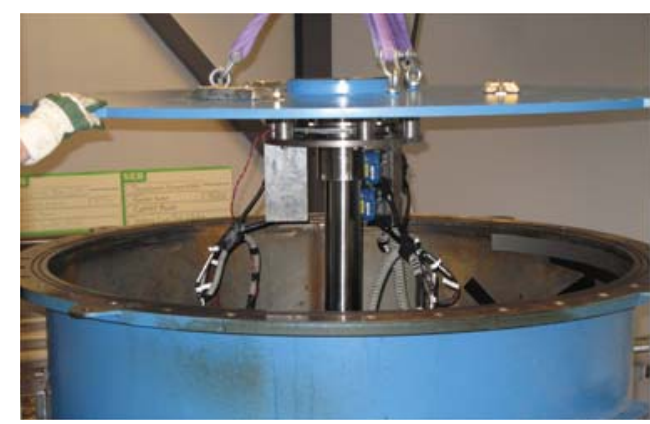

(j)

FIGURE 14: (a) Rectangular plate for mounting sensors, (b) 3 threaded holes for M10-bolts and 2 slots for guide pins in a rectangular plate, (c) M4-bolts with Nord-Lock washers for fastening sensors, (d) 6 sensors visibly mounted to the rectangular plates, with the 7th sensor mounted to the back of the right plate, (e) rectangular plates with sensors in position for attachment of circular sheave, (f) sensor set-up rig enabling fixed relative sensor positions, (g) sensor set-up rig mounted underneath the capsule top plate with the mechanical lead-through in the centre, (h) same as $14 \mathrm{~g}$ but viewed from underneath, (i) complete set-up with sensors connected to the data acquisition system, and (j) final assembly of the top plate to the capsule with the piston rod sliding through the seal housing and the sensor set-up rig closing in on its final position inside the WEC.

back of one of the plates. It measures through an opening in the circular sheave; see Figures 14(e), 14(f), and 14(g). The M4-bolts are penciled with Loctite metal epoxy for increased fixation to the mounting holes in the sensor casings and for filling out the play in the $\varnothing 4.5 \mathrm{~mm}$ holes. The M4-bolts were fitted with Nord-Lock washers to maintain the prestress in the joints to further secure the positions; see Figure 14(c).

The rigidity of the set-up rig is based on the use of thick steel parts, prestressed bolted joints, and state-of-theart threadlocking $[69,70]$. The three rectangular plates are very stiff for the application, with dimensions $208 \times 112.3 \times$ $30 \mathrm{~mm}$. The circular sheave is $16 \mathrm{~mm}$ thick with an outside diameter of $430 \mathrm{~mm}$ and inside diameter of $198 \mathrm{~mm}$. The rectangular plates, on which the sensors are mounted, are bolted to the circular sheave with three M10-bolts into each plate using both Loctite 243 threadlocker and Nord-lock washers to hold them rigidly fastened; see Figures 14(b), $14(\mathrm{c})$, and $14(\mathrm{f})$.

The 3 rectangular plates are very accurately positioned by the use of 2 guide pins. The guide pins are fitted through the circular sheave and into each plate; see the two smaller holes in Figure 14(b). The guide pins regulate the angular position between the plates and the radial distance from the $z$-axis, that is, the centre axis of the laser sensor set-up rig. Figure 14(f) shows the sensor set-up rig in its entirety, the assembly responsible for keeping the relative positions 
between the sensors fixed to enable the relative displacement measurements in common mode.

The set-up rig in Figure 14(f) is bolted to the six support bars in Figure $14(\mathrm{~g})$ with six M12-bolts, one into each support bar. A $35 \mathrm{~mm}$ free prestress length on the bolts inside the support bars maintains the prestress. The Nord-Lock washers secure the lock and the rigidity of the joints. The six support bars are welded to the top plate and milled in one operation to achieve absolute parallel surfaces at the same level. The positioning of the support bars was carried out with the help of a large coordinate table. The inside edge of the capsule top plate centre opening was used as a reference. Figure 14(h) displays the angular and radial positions of the plates and the sensors after the set-up rig was mounted underneath the capsule top plate.

The complete sensor set-up with the sensors connected to the data acquisition system is displayed in Figure 14(i) just before final assembly and closing of the generator capsule. The sensors are supplied with power and fully operational. The first $20 \mathrm{~cm}$ of the screened sensor cables are fitted with thick stiff shrinking tubing. They are thus separated from interfering with the experiment and prevented from getting entangled with the measured objects. Inside the WEC the cables are further protected by plastic spiral protection. The free cables are short enough to remain on top of the upper end stop structure. Figure 14(j) displays the final closing of the capsule with the top plate lowered down and the top of the piston rod sliding through the seal housing.

4.6. The Data Acquisition System. The data acquisition system performs the task of converting the analogue voltage output from the laser triangulation sensors and the draw wire sensor in the offshore WEC to digital data available onshore. Analogue data is sent from the WEC to the underwater substation where it is digitized. From the substation digital data is sent to a PC in the onshore measuring station where it is stored on an external hard disk drive.

The analogue voltage output from the laser sensors ranges between 0 and $10 \mathrm{~V}$. This represents $0-20 \mathrm{~mm}$ measuring range. The sensors sample at $312.5 \mathrm{~Hz}$. The analogue voltage outputs are sent through screened cables to individual instrumentation amplifiers (in-amps) installed in the WEC. The in-amp used is an AD622 from Analog Devices Inc. [71]. The AD622 amplifies the analogue voltage by a gain factor of 2.8. The signal is amplified in the WEC to increase the signal-to-noise ratio during the transfer to the offshore underwater substation. This is done through 7 individual twisted pairs in a $70 \mathrm{~m}$ long sea cable. The twisted pairs in the sea cable screen the voltage signal from external electromagnetic noise. The AD622 IC cards in the WEC are protected from the environment by varnish and a metal casing connected to ground. The casings are filled with a butadiene casting compound, denoted by Guronic C400.

The amplification circuit has an output voltage swing of $\pm 15 \mathrm{~V}$. An offset of $5 \mathrm{~V}$ is established to set the zero output at the level of $5 \mathrm{~V}$ input. The voltage input of $0-10 \mathrm{~V}$ is thereby converted to $\pm 14 \mathrm{~V}$ output by using almost the entire output voltage swing of the amplification circuit. The increase in precision is favored compared to a common ground at the edge of the measurement range. The system calibration will sort out the distance to voltage relations and the result of this can be viewed in Figures 17(a)-17(g) in Section 4.7.

Once the amplified analogue voltages from the AD622s in the WEC reach the offshore underwater substation, resistive damping circuits reduce the voltage by a factor of 0.5 to $\pm 7 \mathrm{~V}$ in order to match the input voltage limits $( \pm 10 \mathrm{~V})$ of a Programmable Automation Controller (PAC). The PAC in question corresponds to what is denoted by "PAC 3 " in the control and measurement system of the offshore underwater substation, as described by Svensson et al. [20].

The PAC consists of three major parts: a realtime controller with real-time operating software, a Field Programmable Gate Array (FPGA) chip, and different input/output modules. The FPGA chip is mounted inside the backplane of a CompactRIO system from National instruments. The PAC in the substation controls the data acquisition system and samples input voltage between $\pm 10 \mathrm{~V}$ at a frequency of $256 \mathrm{~Hz}$. The sampling frequency is chosen, mainly to be able to synchronize the measurements from WEC L2 and L3 with the measurement system in the buoys which samples at a rate of $16 \mathrm{~Hz}$.

The PAC samples simultaneously on all 7 laser sensor channels with a sampling period of $3.9 \mathrm{~ms}(1 / 256 \mathrm{~Hz})$. It samples with a frequency that is $56.5 \mathrm{~Hz}$ lower than that of the sensors. This will result in a complete overlap and loss of a sample after every 4.53 samples $(256 / 56.5)$ or every $17.7 \mathrm{~ms}\left(4.53^{*} 3.9\right)$. The frequency mismatch between the sensors and the PAC will result in a loss of $18 \%(1 /(4.53$ $+1)$ ) of the samples. The mismatch will not affect the measurement accuracy. A synchronization error will however occur between the individual sensors and will cap at $1.6 \mathrm{~ms}$, that is, half the sensor sampling period.

After sampling simultaneously on 7 channels the PAC $\mathrm{A} / \mathrm{D}$ converts the analogue voltages to $64 \mathrm{kbit}$ digital voltage signals. A mathematical function in the PAC Labview software amplifies the digital voltage signals to match the voltage output from the AD622s in the WEC. The measuring system, including the $70 \mathrm{~m}$ long sea cable, was generally calibrate with a voltmeter APPA 207 [72], with a basic accuracy of $0.7 \%$, in order to calibrate the Labview amplification in the PAC. This calibration was then overridden by a system calibration (end-to-end calibration) where digital distance values from the laser sensors were compared to the measured digital voltage values from the PAC in the offshore underwater substation. The override was done in order to include the amplification cards in the WEC and to increase the accuracy of the overall measuring system; see Section 4.7.

The digital output voltages from the PAC are sent with a point-to-point copper link from the offshore underwater substation through a separate $3 \mathrm{~km}$ long sea cable to the onshore measuring station. At the measuring station the receiving Ethernet SHDSL.bis modem transmits the data to a PC which stores it on an external hard disk (HD) drive. The entire data acquisition system for the laser sensor measurement system, from the sensors in the offshore WEC to the external HD drive at the onshore measuring station, is displayed in Figure 15. 


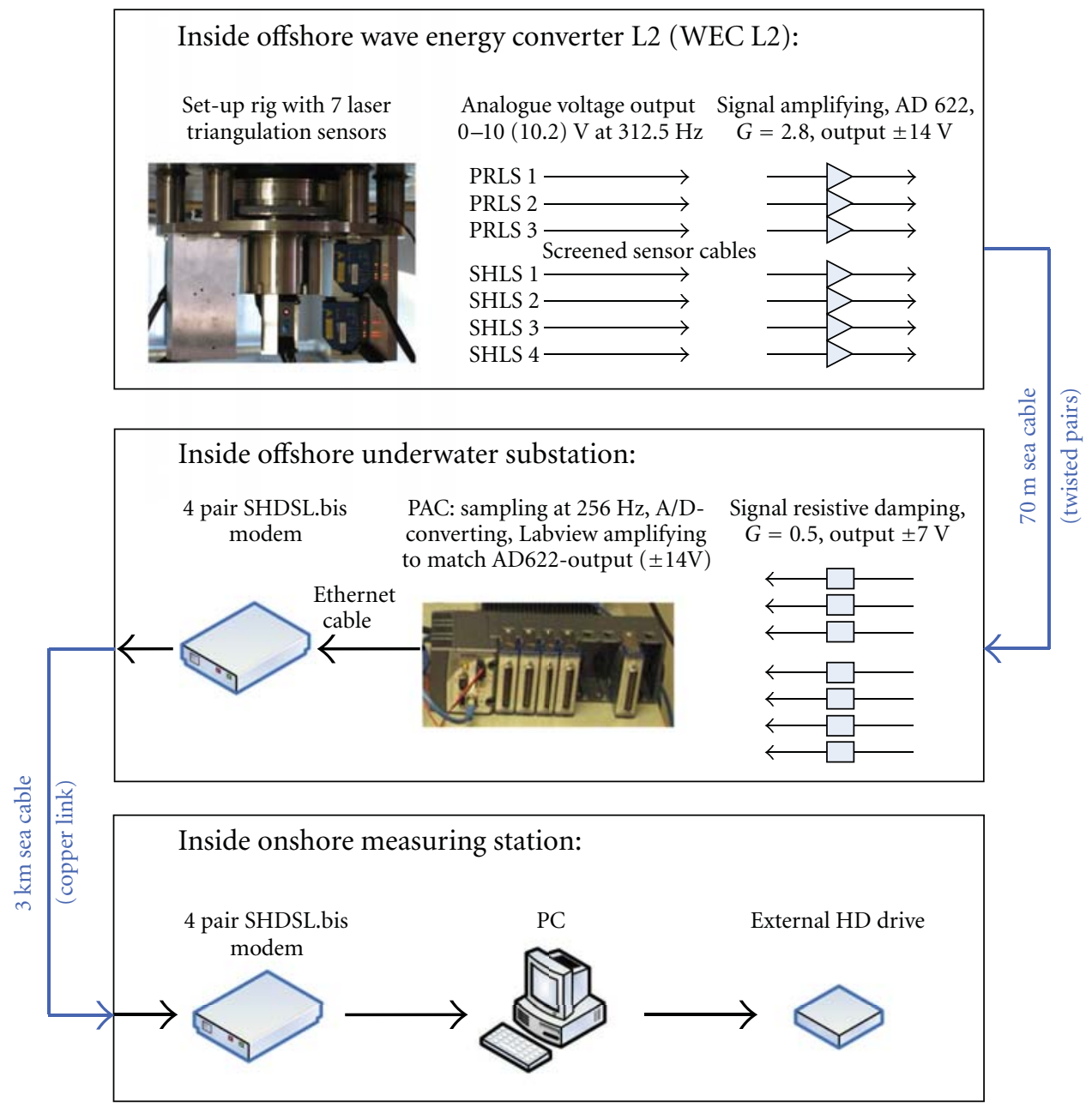

FIgURE 15: The data acquisition system for the laser sensor measurement system, between the sensors in the offshore WEC and the external HD drive at the onshore measuring station.

The PAC is digitizing 15361 voltage values from each sensor every minute. Each data file contains one minute of data. Each file is tagged with date, hour, and minute. From these values chosen intervals can be studied and correlated with data from other sensors or power data from the WEC, which have been sampled by the same PAC at the exact same time. The draw-wire sensor is one example that uses the same data acquisition system. It uses one channel and an AD622 of its own with a signal gain factor of 2.0.

All sensors and in-amps in the WEC are supplied with $24 \mathrm{VDC}$ from two serial connected $12 \mathrm{~V}$ batteries mounted inside the offshore underwater substation. The power is supplied through the $70 \mathrm{~m}$ long signal sea cable from the offshore underwater substation to various DC/DC converters in the WEC supporting the sensors with their required voltages.

There is a certain level of common mode rejection of disturbances between the output of the sensors and input of the AD622 in the WEC, but the ratio is small since the sensors have no differential output. The sensor analogue output is connected to the non-inverting input (+) of the AD622. The sensor AGND (the reference potential for analogue output) is connected to the inverting input (-) of the AD622. The AGND is not directly connected to the power supply GND (ground), but through a decoupling capacitor inside the sensor. Due to the connection between the AGND and the power supply GND, a common transient disturbance on the output and the AGND will not result in the same disturbance amplitude. Hence this will only result in a slight common mode rejection of the disturbance.

4.7. System Calibration of the Laser Sensor Measuring System. Each laser sensor is factory calibrated by the manufacturer and individual calibration protocols are supplied with each sensor; see Figure 23 in Section 6.1.1. The measuring system from the $70 \mathrm{~m}$ long sea cable to the PAC output is calibrated together, as mentioned in Section 4.6. The amplification cards in the WEC are not calibrated separately. The accuracy of the amplification cards is therefore set by the tolerance of the components. This tolerance is quite big compared to the accuracy of the sensors. Therefore a system calibration is needed. Even if the amplification cards would be calibrated, 


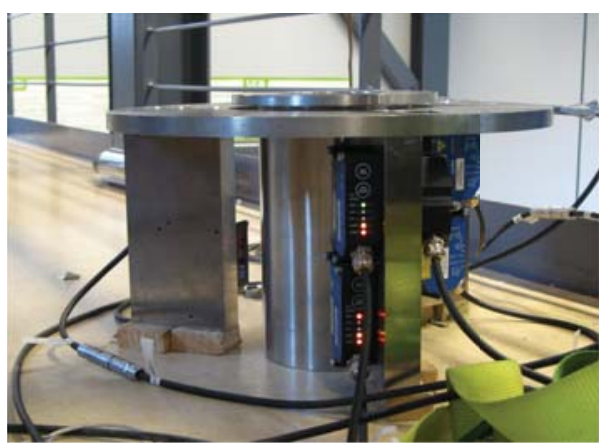

(a)

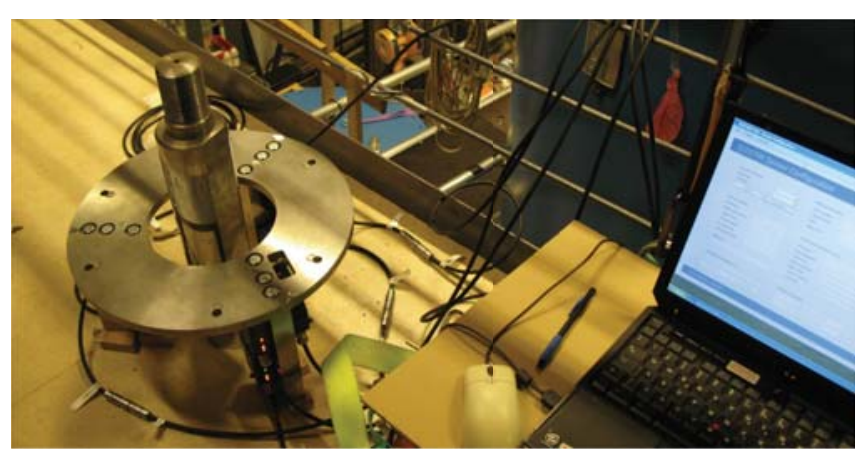

(b)

FIgURE 16: System calibration of the laser sensor measuring system from laser sensor to PAC output with two different calibration objects. (a) The flanged stainless steel cylinder in position for SHLS 1-4. (b) The short stainless steel rod in position for PRLS 1-3.

system calibration increases the accuracy because the inaccuracy from each separate calibration does not need to be added to reach the total accuracy of the entire laser sensor measuring system.

After the laser sensors are mounted onto the set-up rig, each is system calibrated (or end-to-end calibrated) together with the rest of the measuring system. 7 individual transfer functions, one for each laser sensor, are generated to establish a mathematical relationship between the digital output voltage from the PAC and the measured distance. The output voltage from the PAC is equivalent to the data being logged during operation on the external $\mathrm{HD}$ drive in the measuring station. There will be no additional inaccuracy influencing the digital signal once it has been digitized in the PAC. The rest of the data acquisition system from PAC output to onshore logging and storing of data on the external HD drive is unnecessary to include in the system calibration.

System calibration of the laser sensor measuring system from sensor and to PAC output was performed at an ambient temperature of 19 degrees in the assembly hall at Uppsala University. Before system calibration the laser sensors were mounted and fixed in their final positions on the set-up rig, as described in Section 4.5. A warm-up time of 30 minutes was then awaited to achieve a stabile sensor temperature.

A short stainless steel rod was used as calibration object for the system calibration of PRLS 1-3; see Figure 16(b). A flanged stainless steel cylinder, resembling the seal housing, was used to system calibrate SHLS 1-4; see Figure 16(a). The real piston rod was deemed too long, too impractical to handle, and too easily damaged to use for the system calibration procedure. The real seal housing was unavailable at the time.

It is generally important to use the same kind of target surface to ensure accuracy [38]. In our case, system calibration cannot be performed with the real piston rod and seal housing installed in the WEC. The required variations of the object positions along the individual measuring range for each sensor cannot be accomplished due to limitations within the WEC. Both chosen calibration objects are however very suitable for the system calibration since they are both made of stainless steel with the same reflectance, the same diameters (target surface curvature), and similar surface roughness.

System calibration is performed in two steps for each calibration object and corresponding group of sensors (PRLS 1-3 or SHLS 1-4). The first step consists of measuring the distance between each sensor and its target surface by directly connecting it to a portable PC with the digital RS 422/USB cable. In order to connect a sensor to the PC the sensor is temporarily reconfigured for digital value output. The calibration object is positioned and kept stationary within range of all the sensors within the group. Each sensor within the group is then in turn connected to the PC. Sensor supplier software in the PC displays a stabile distance value in $\mathrm{mm}$ with 3 digits for each connected sensor. The stability of the 3 digits signifies the high accuracy of the sensor itself, which almost coincides with the resolution; see Table 1 and Figure 23. Only sensor nonlinearity from factory calibration separates this measured distance from the true distance.

The second step in the system calibration is performed immediately after the first step. The RS422/USB cable is removed. The sensors are reconfigured for analogue voltage output and connected to their individual designated cable and channel in the measuring system. The calibration object is still left untouched in the exact same position. Each sensor then transmits analogue voltage through the measuring system to the PAC. The PAC samples 15361 voltage values and delivers a digitized output with a 2-digit resolution.

In conclusion, a system calibration procedure, with the calibration object stationary in one position, generates one distance value and 15361 corresponding PAC output voltage values for each sensor. The system calibration procedure is first repeated 4 times for PRLS 1-3 with the short stainless steel rod standing vertical in 4 different horizontal positions within range of all 3 sensors; see Figure 16(b). The same system calibration procedure is then repeated 4 times for SHLS 1-4 with the flanged stainless steel cylinder, resembling the seal housing, stationary and vertical in 4 different horizontal positions within the range of all 4 sensors; see Figure 16(a).

From the 15361 voltage values a mean output voltage can be calculated. The combination of a distance value and 


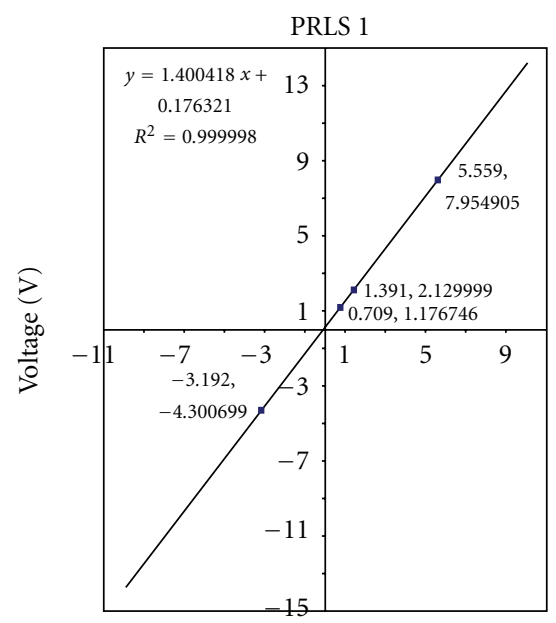

Distance from $\operatorname{MMR}(\mathrm{mm})$

(a)

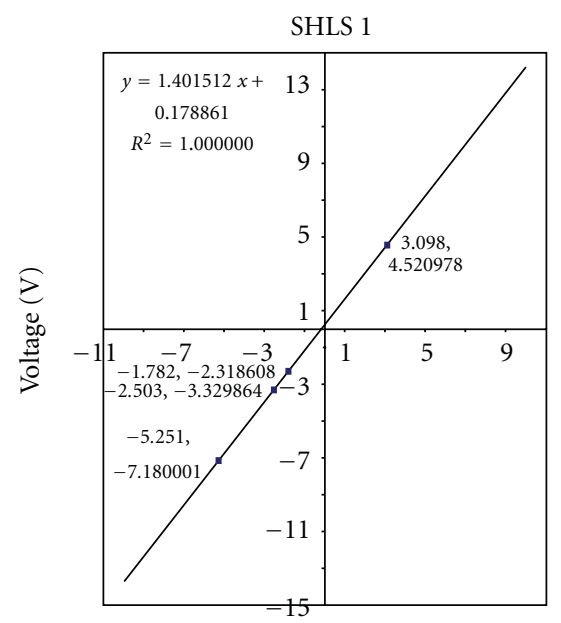

Distance from MMR(mm)

(d)

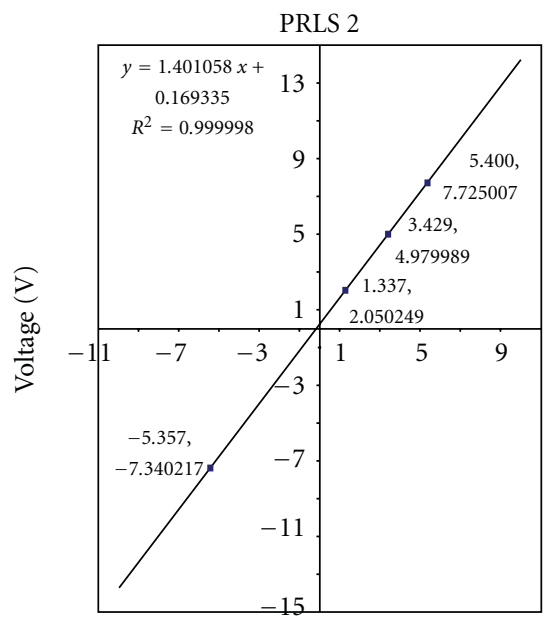

Distance from MMR(mm)

(b)

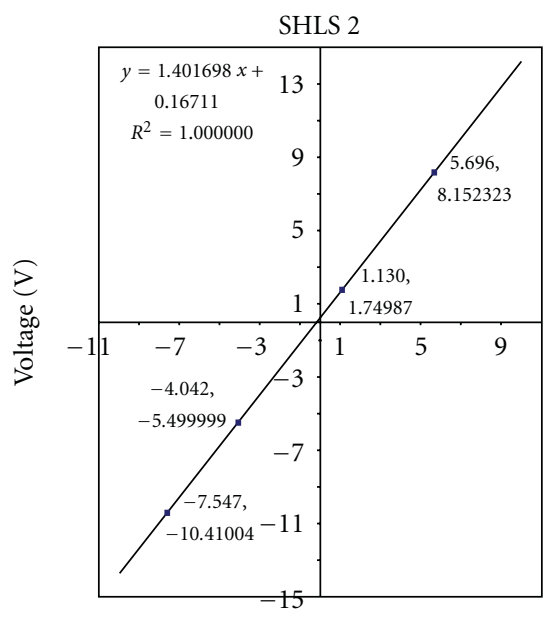

Distance from MMR(mm)

(e)

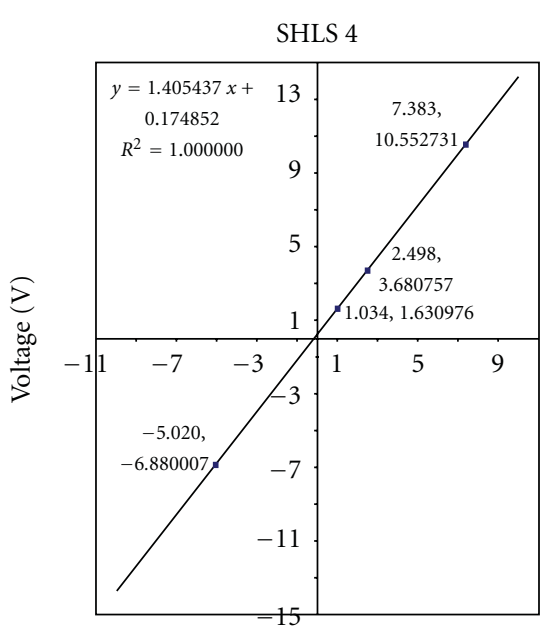

Distance from MMR(mm)

(g)

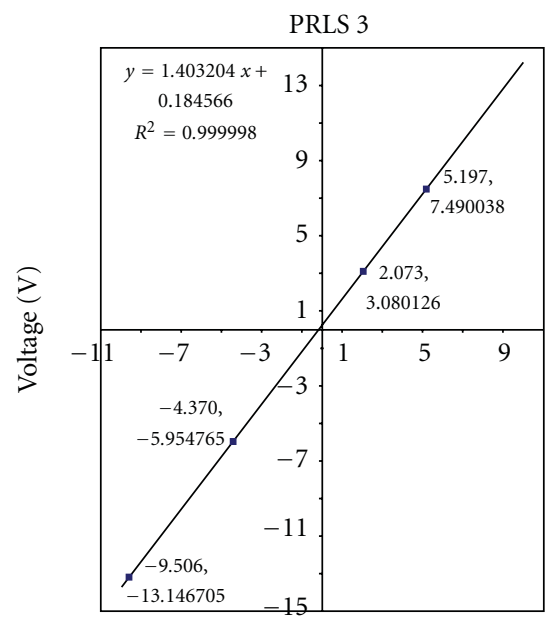

Distance from $\mathrm{MMR}(\mathrm{mm})$

(c)

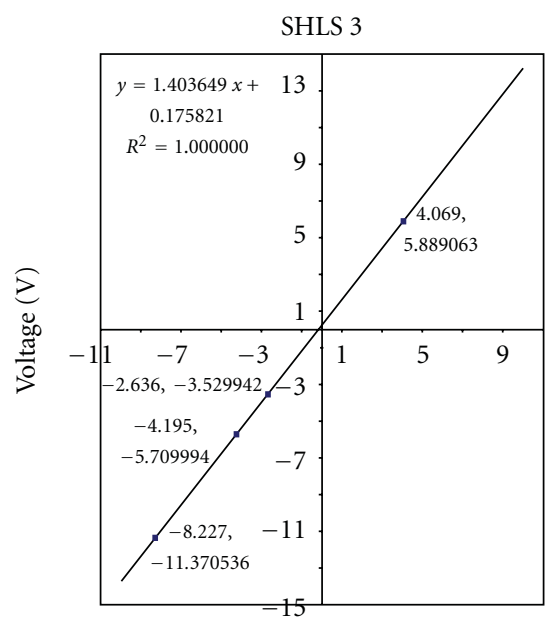

Distance from MMR(mm)

(f) 


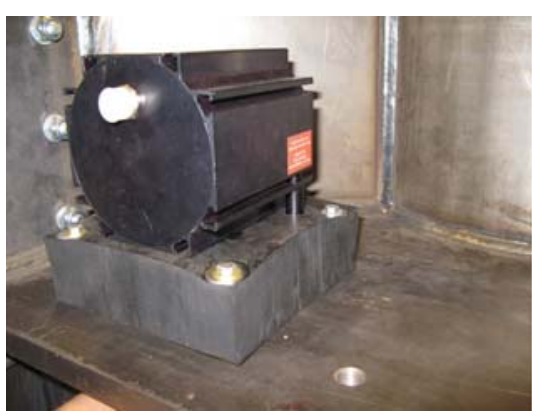

(a)

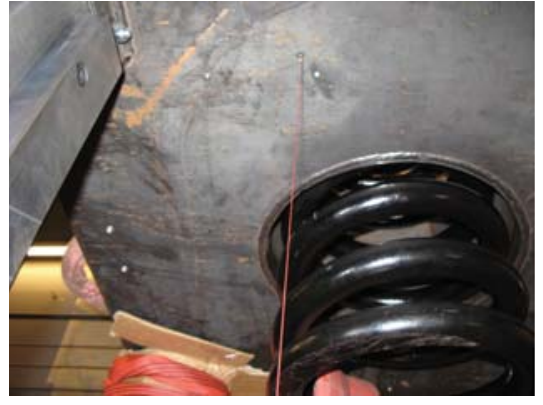

(b)

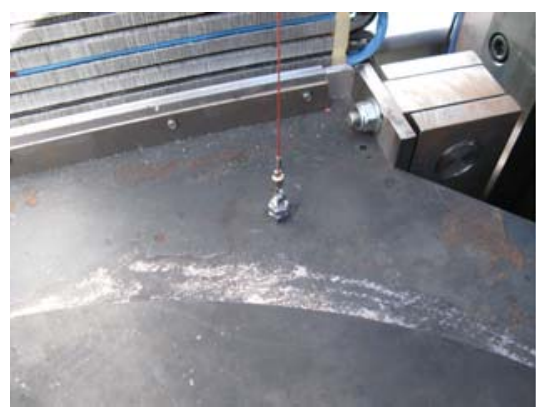

(c)

Figure 18: (a) Draw-wire sensor on rubber mat bolted to the upper end stop, (b) red wire moving through the upper end stop, and (c) draw-wire attached to the upper surface of the translator.

a corresponding mean voltage value constitutes a so-called calibration point. 28 calibration points are generated for all 7 laser sensors with 4 calibration points for each sensor in the graphs of Figures 17(a)-17(g). The distance is given in $\mathrm{mm}$ along the $x$-axis and the voltage in volts along the $y$-axis. The standard error of the mean voltage for each calibration point and sensor is presented in Table 3 of Section 6.4.1.

Transfer functions are now generated through linear regression. A linear regression line is fitted to the 4 calibration points in each graph using the least squares method. The graphs in Figures 17(a)-17(g) display the transfer functions and the corresponding $R^{2}$-coefficients, or coefficients of determination, with 6 digits [73]. The $R^{2}$-coefficients indicate an almost perfect regression between the linear transfer functions and the calibration points, especially for SHLS 1-4.

The 2-digit resolution in the $15361 \mathrm{PAC}$ output voltage values was a chosen precision at the time of the system calibration. It was a chosen level of precision for the purpose of maintaining good data transfer from all sensors during offshore operation without latency in the digital point-topoint copper link. However, twelve days after launch, on the 27th of May at 22:58 hours, the number of digits was changed to 3 by remote reprogramming of the PAC in order to increase precision. Even though 2 digits are used for the 15361 voltage values during system calibration, an increased sub-2nd digit resolution is achieved with the 6 digits in the mean voltage values. The increased resolution is caused by interpreting the distribution of adjacent voltages on the 2 nd digit of all the samples.

The curve fitting of the transfer functions is not weighted with regard to the inverse of the variances. The high number of voltage samples suggests a normal distribution. However, the 2-digit resolution causes an irregular distribution over just 2-4 integers on the last digit. These 2-4 integers are crude for calculating variances and cause unreliable and unrealistically large or small weights depending on where the mean output voltage is positioned in the interval. Instead, the increased sub-2nd digit resolution of the mean output voltage becomes a more accurate estimation for unweighted curve fitting. See Section 6.4.1 for further analysis.
The linear transfer functions will later be used in reverse, as $x=(y-b) / a$, in order to calculate the change in linear distance (or relative displacement) of the target surfaces as measured by each sensor. The functions will be applied to the stored voltage values in the external HD drive at the onshore measuring station with samples from an entire wave period or more.

The sensor error voltage of $10.2 \mathrm{~V}$, indicating a faulty measurement, was also amplified and a mean was calculated to approximately $13.8 \mathrm{~V}$ based on 15361 voltage values logged by the PAC for each sensor. Since the error voltages do not represent a distance, they are excluded from being calibration points for the generation of transfer functions.

4.8. Mounting and Calibration of the Draw-Wire Sensor Measuring System. The draw-wire sensor measures the axial position and displacement of the piston rod and translator. The output from the laser triangulation sensors can be correlated with the output from the draw-wire sensor to interpret the performance of the piston rod mechanical lead-through transmission. Draw-wire sensors connected to mechanical applications, and comments on calibration, have been found in scientific literature [74, 75] and commercial online material [76] but have to the authors' knowledge not been used before inside an offshore linear WEC.

The draw-wire sensor inside L2 is mounted on a $50 \mathrm{~mm}$ thick rubber mat and bolted to the top side of the upper end stop; see Figure 18(a). The rubber mat is used as a damper to secure the inside electronics from large vibrations. The mounting of the draw-wire sensor involves drilling a hole through the upper end stop for the wire to move through; see Figure 18(b). The wire is made of stainless steel with a red polyamide sheath. It is pulled down and attached to a screw in the periphery on top of the translator; see Figure 18(c).

The draw-wire sensor is factory calibrated by the manufacturer and a nonlinearity is given as $\pm 3 \mathrm{~mm}$ ( or $\pm 0.1 \%$ of FSO) [62]. The calibration of the draw-wire sensor measuring system in L2 was first done inside the assembly hall at $19^{\circ} \mathrm{C}$ with the translator in two different positions compared to the stator; see first and second rows in Table 2 and Figures 19(a) and 19(b). There were some practical 
TABLE 2: Calibration protocol for the draw-wire sensor measuring system.

\begin{tabular}{|c|c|c|c|c|c|}
\hline $\begin{array}{l}\text { Positions for translator and piston } \\
\text { rod during calibration of the } \\
\text { draw-wire sensor in WEC L2 }\end{array}$ & $\begin{array}{l}\text { Length from bottom } \\
\text { of translator to } \\
\text { bottom of stator } \\
(\mathrm{mm})\end{array}$ & $\begin{array}{l}\text { Length from top of } \\
\text { translator to top of } \\
\text { stator }(\mathrm{mm})\end{array}$ & $\begin{array}{l}\text { Length to translator } \\
\text { bottom position } \\
(\mathrm{mm})\end{array}$ & $\begin{array}{l}\text { Piston rod length } \\
\text { above the top of the } \\
\text { seal housing }(\mathrm{mm})\end{array}$ & Voltage (V) \\
\hline $\begin{array}{l}\text { The bottom of the translator in line } \\
\text { with the bottom of the stator, } \\
\text { Figure } 19 \text { (a) }\end{array}$ & 0 & 603 & 1361.5 & 1486.5 & 2.850 \\
\hline $\begin{array}{l}\text { The top of the translator in line with } \\
\text { the top of the stator, Figure } 19 \text { (b) }\end{array}$ & 603 & 0 & 758.5 & 883.5 & 4.734 \\
\hline $\begin{array}{l}\text { lst measurement on piston rod, } \\
\text { Figure } 19(\mathrm{~d})\end{array}$ & 643.5 & 40.5 & 718 & 843 & 4.940 \\
\hline $\begin{array}{l}\text { 2nd measurement on piston rod, } \\
\text { Figure } 19(\mathrm{e})\end{array}$ & 1265.5 & 662.5 & 96 & 221 & 6.900 \\
\hline
\end{tabular}

(a)

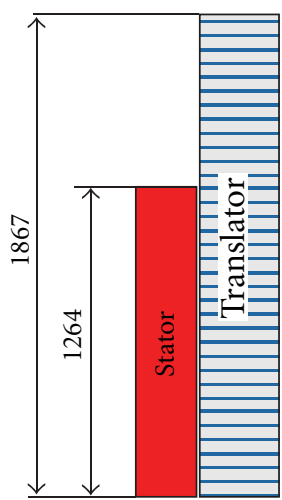

(b)

(c)
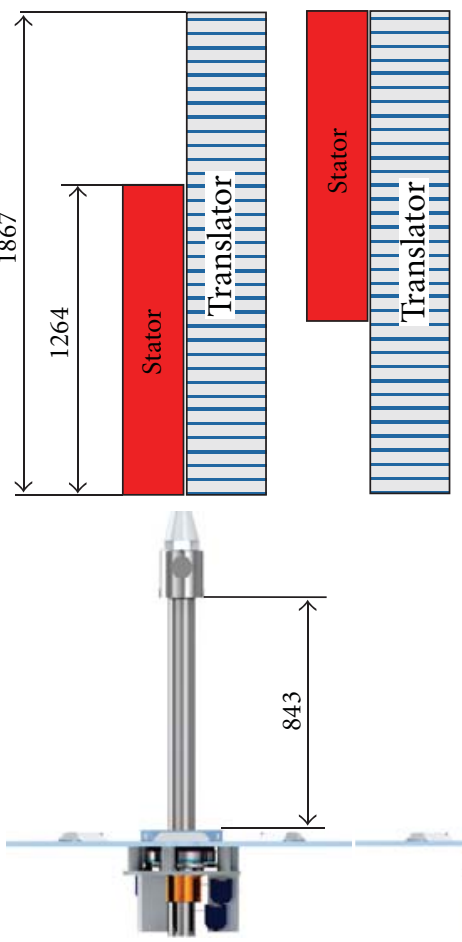

(d)
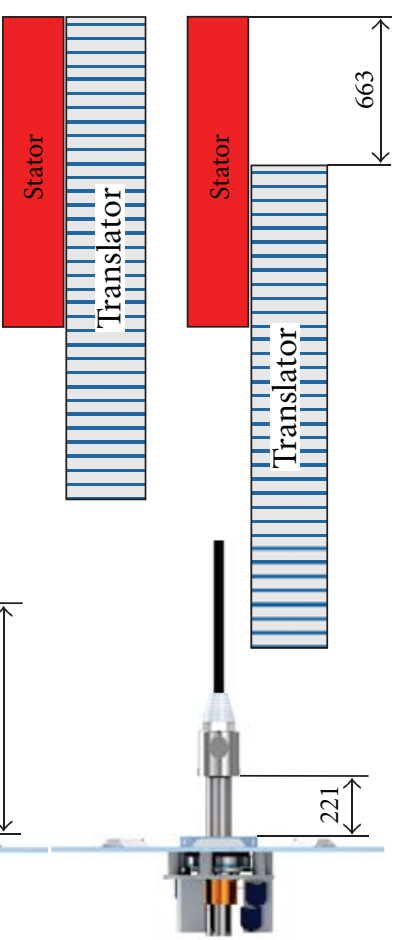

(e)

Figure 19: Illustrations of the relative positions of the translator and the stator, and of the piston rod outside lengths during calibration of the draw-wire sensor. Figure 19(c) represents the translator position used for validation $(\mathrm{mm})$.

difficulties in establishing the correct translator position in relation to the stator, since the open capsule surrounded the generator at that point. This led to the use of a second calibration method, which was adopted after the top plate was mounted to the capsule with the WEC still remaining in the assembly hall at $19^{\circ} \mathrm{C}$. The piston rod outside length on above the seal housing was measured with a scale with $\mathrm{mm}$ resolution at two different vertical positions, according to Figures 19(d) and 19(e). The corresponding draw-wire

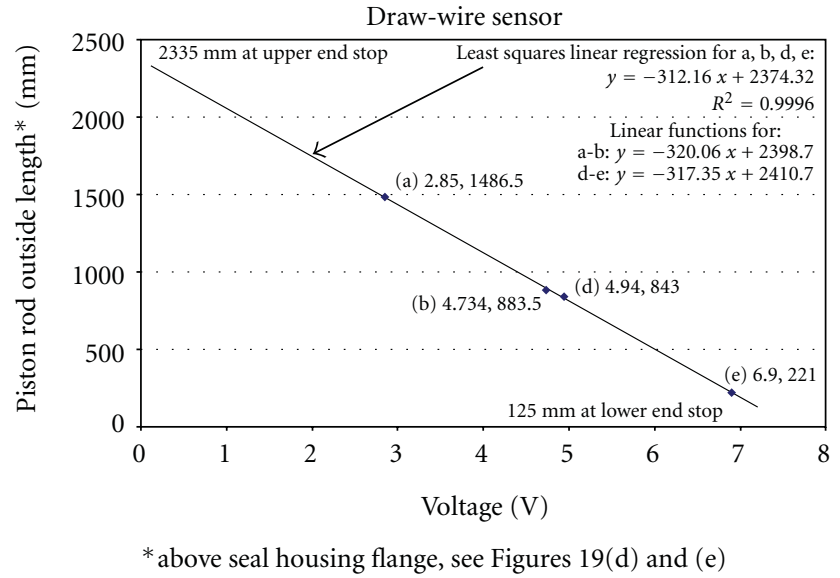

Figure 20: Three transfer functions relating PAC output voltage $(x)$ from the draw-wire sensor to piston rod outside length $(y)$ above the seal housing flange. The seemingly most accurate transfer function is the one given as $y=-317.35 \cdot x+2410.7$ based on points $\mathrm{d}$ and $\mathrm{e}$.

sensor output from the AD622 in-amp was measured with a Fluke 187 digital RMS multimeter [77]; see Table 2.

The rest of the measuring system including the $70 \mathrm{~m}$ sea cable and the mathematical Labview amplification in the PAC had already been calibrated with APPA 207 to equal the voltage output from the AD622 in-amp in the WEC; see Section 4.6. The total accuracy for the calibration of the draw-wire sensor measuring system is therefore achieved by adding the inaccuracies from both calibration procedures; see Section 6.4.2.

Three transfer functions are presented in Figure 20 relating PAC output voltage from the draw-wire sensor to piston rod outside length above the seal housing flange. A least square-fitted regression line represents the transfer function based on all 4 calibration points in Table 2. The first and second calibration methods generate separate linear transfer functions between points a-b and d-e. The $R^{2}$-coefficients for the transfer function with all 4 calibration points show good linear regression, but possible inaccuracies in the alignment between translator and stator in the first calibration method 
seem to cause inaccuracies in the translator position when comparing experimental data with the physical end stop boundaries in the WEC. The most accurate transfer function seems to be the one for the second calibration method based on points $\mathrm{d}$ and $\mathrm{e}$.

Figure 19(c) displays the top of the translator $663 \mathrm{~mm}$ below the top of the stator. In this case the translator and the piston rod transmission rests on the lower end stop compression spring, which has a spring constant of $211.6 \mathrm{~N} / \mathrm{mm}$. The spring constant is established through a compression test of the specific spring in L2 performed by the manufacturer prior to delivery. In its unloaded state the compression spring sticks up $200 \mathrm{~mm}$ above the lower end stop. Figures 19(c) and 19(e) represent the same case with a measured piston rod outside length of $221 \mathrm{~mm}$, placing the translator $127 \mathrm{~mm}$ above the lower end stop, according to the CAD assembly model. This corresponds to a spring compression of $73 \mathrm{~mm}$ (200-127 mm). The compression requires a mass of $1575 \mathrm{~kg}$ weighing down on the lower end stop compression spring.

The mass of the translator can be calculated to $1152 \mathrm{~kg}$ by using mass analysis in the CAD assembly software and by using product catalogues for the fasteners. The mass is verified in the assembly hall with a 5-ton Teo-scale with an accuracy of $\pm 1 \%$ of FSO of [78]. The other parts weighing down on the compression spring add up to approximately $471 \mathrm{~kg}$. This includes the 8 retracting tensile springs $(288 \mathrm{~kg})$, the motion restricting cylinder $(36 \mathrm{~kg})$, the double-hinged link $(7 \mathrm{~kg})$, the piston rod $(106 \mathrm{~kg})$, and the lower and upper rod end clevises (19 and $22 \mathrm{~kg}$ ). The total mass amounts to $1623 \mathrm{~kg}(1152+471 \mathrm{~kg})$, with an estimated accuracy of $\pm 10 \mathrm{~kg}$. This would result in a spring compression of $75.3 \mathrm{~mm}$ and a piston rod outside length of $218.7 \mathrm{~mm}$. The difference between the calculated and the measured piston rod outside length is $2.3 \mathrm{~mm}$ (221-218.7). This translates into approx. $50 \mathrm{~kg}$, which is justified by the static friction force between the piston rod and the dynamic sealing system, the static friction force within the 24 yoke type track rollers, and the tangential magnetic force between the stator and translator.

\section{Results}

5.1. Sea State during Measurements. The waves at the LRS are measured by a nondirectional Datawell Waverider buoy [12]. The buoy measures the vertical surface displacement and sends the information through radio link to the Sven Lovén Centre for Marine Studies in Fiskebäckskil. The measurement frequency is $2.56 \mathrm{~Hz}$. Spectral analysis is carried out on shore. The overall accuracy of the buoy is $3.5 \%$ of the measured value. A significant wave height $\left(H_{s}\right)$, a mean energy period $\left(T_{e}\right)$, and a wave power density $(J)$ are calculated as half-hourly averages. The first set of results in Section 5.2 were logged on the 28th of May between 14:00 and 14:30 hours with a sea state of $H_{s}=1.6 \mathrm{~m}, T_{e}=6 \mathrm{~s}$, and $J=7.3 \mathrm{~kW} / \mathrm{m}$. The second set of results were logged on the 15th of August between 01:00 and 01:30 hours with a similar sea state of $H_{s}=1.55 \mathrm{~m}, T_{e}=5.8 \mathrm{~s}$, and $J=6.7 \mathrm{~kW} / \mathrm{m}$.
5.2. Sensor Output with Centred Moving Averages. The measurement results are presented as sensor output converted from voltage to distance from midrange (MMR), that is, displaying relative displacement, and piston rod outside length in the time domain. The motion in Figures 21(a)$21(\mathrm{~h})$ is measured between $14: 10$ and 14:11 hours on the 28th of May. The motion in Figures 22(a)-22(h) is measured between 01:01 and 01:02 hours on the 15th of August. Centered moving averages, averaging over 51 values, are superimposed in red color.

A moving average is optimal for reducing random white noise while keeping the sharpest step response in the time domain [79]. The amount of noise reduction is equal to the square-root of the number of values in the average, in other words the square-root of 51. A small attenuation of the peaks might appear, but there will not be any time shift (lag) since the moving average is centered. A moving average cannot, however, separate one band of frequencies from another. It has a slow roll-off rate and very poor stop band attenuation in the frequency domain.

The choice of averaging over 51 values was made through visual iteration. The aim was to smooth out high-frequency transmitted noise, from external sources in the environment, and inherent noise, generated in the sensors and the data acquisition system, as well as speckle in the laser sensor output. On the other hand, the aim was also to keep signs of vibration from generator cogging and other low-frequency mechanical vibrations that might affect the motion of the objects. Future work will entail spectral analysis and filtering of the sensor output to investigate the characteristics of the signal.

The two brown horizontal lines in Figures 21(a) and 22(a) represent the piston rod outside lengths at the upper and lower end stops. At the upper end stop the piston rod outside length is $2335 \mathrm{~mm}$ and at the lower end stop it is $125 \mathrm{~mm}$. The two blue horizontal lines inside the brown ones in the same figures represent the piston rod positions when the translator comes into contact with the upper and lower end stop compression springs. When the translator touches the upper end stop compression spring the piston rod outside length is $2092 \mathrm{~mm}$. When it comes into contact with the lower end stop compression spring, the piston rod outside length is $295 \mathrm{~mm}$. The results will be further discussed in Section 7, but before that we will take a look at error estimations, statistical uncertainties, and signal-tonoise ratio.

\section{Uncertainty and Error Estimation}

General sources of influence on measurement error and uncertainty for an optoNCDT 1700 laser sensor are given in [55]. Error and uncertainty in the designed laser sensor measuring system inside the WEC depend on a number of sources: the condition of the target surfaces, the position of the measured objects, the magnitude of the relative displacement, the technical limitations of the sensor, different aspects of the data acquisition system, curve fitting of transfer functions, and post-measurement data processing. 5 sources 


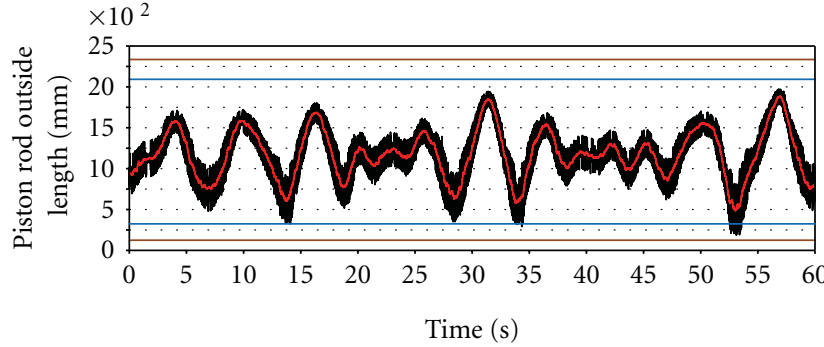

(a)

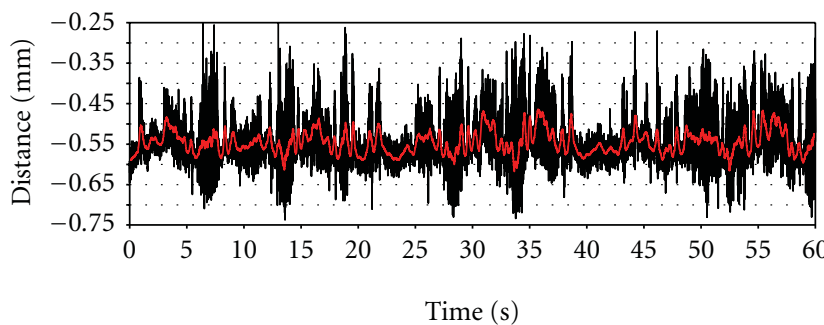

(c)

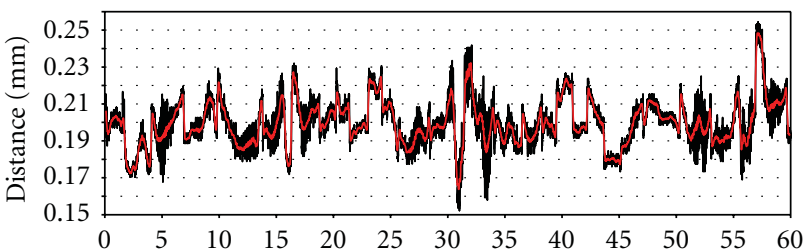

Time (s)

(e)

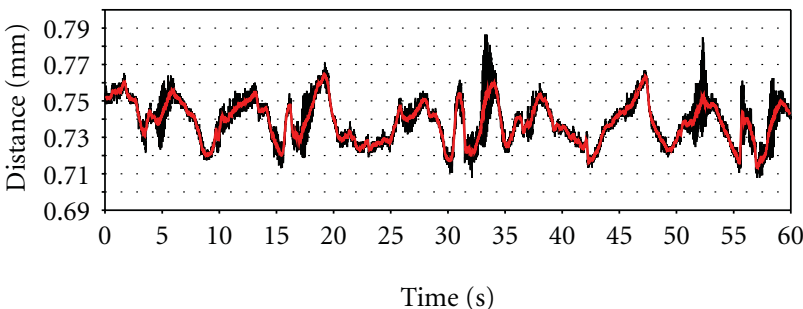

(g)

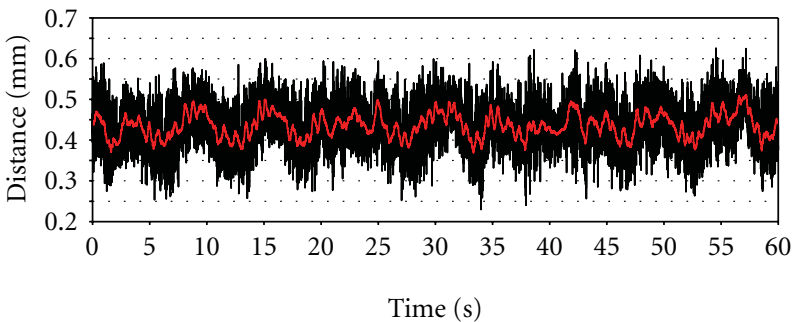

(b)

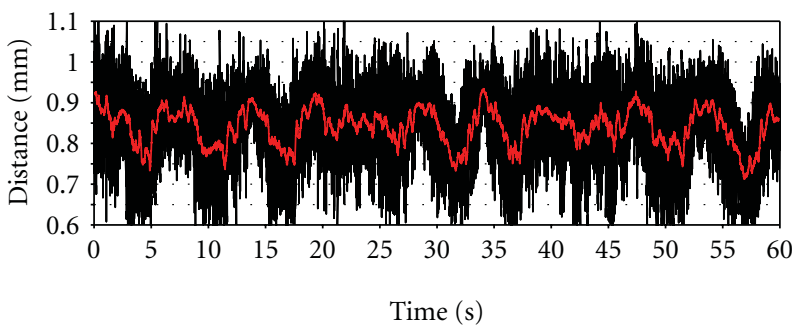

(d)

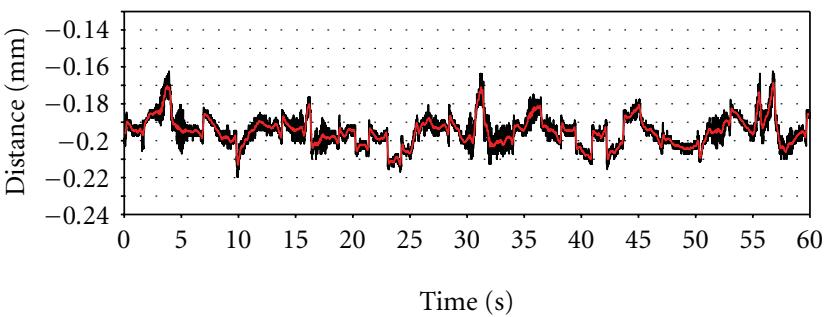

(f)

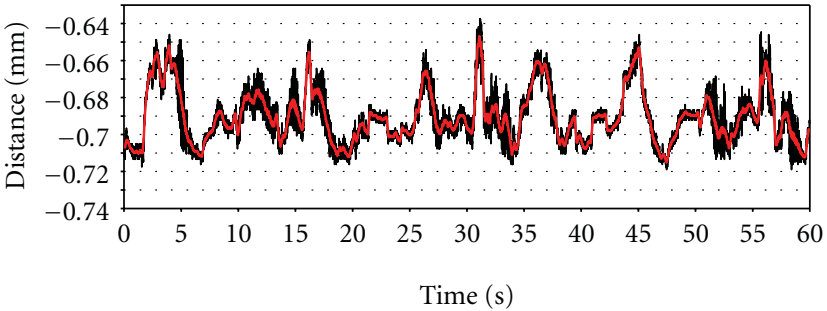

(h)

Figure 21: Sensor output (black) and centered moving averages (red) between 14:10 and 14:11 hours on the 28th of May 2009. (a) Piston rod outside length measured by the draw-wire sensor with free stroke length indicated by two blue lines and maximum stroke length indicated by two brown lines. (b) Distance from middle of measurement range (MMR) towards piston rod surface for PRLS 1. (c) Distance from MMR towards piston rod surface for PRLS 2. (d) Distance from MMR towards piston rod surface for PRLS 3. (e) Distance from MMR towards seal housing surface for SHLS 1. (f) Distance from MMR towards seal housing surface for SHLS 2. (g) Distance from MMR towards seal housing surface for SHLS 3. (h) Distance from MMR towards the bottom surface of the seawater collector, which is attached to the seal housing, for SHLS 4.

have been identified in this experiment. 4 of them, excl. no. 3 below, also apply to the draw-wire sensor measurements:

(1) error due to sensor nonlinearity from factory calibration,

(2) error due to temperature instability,

(3) error due to the influence of a tilting target surface,

(4) uncertainty from system calibration and misfit of transfer functions,

(5) uncertainty due to noise.
The characteristics, the magnitudes, and the influence of these sources will now be described for the laser triangulation sensors and the draw-wire sensor including the measuring system.

\subsection{Error due to Sensor Nonlinearity}

6.1.1. Laser Sensors. The 7 laser triangulation sensors are supplied with factory calibrated protocols displaying a 


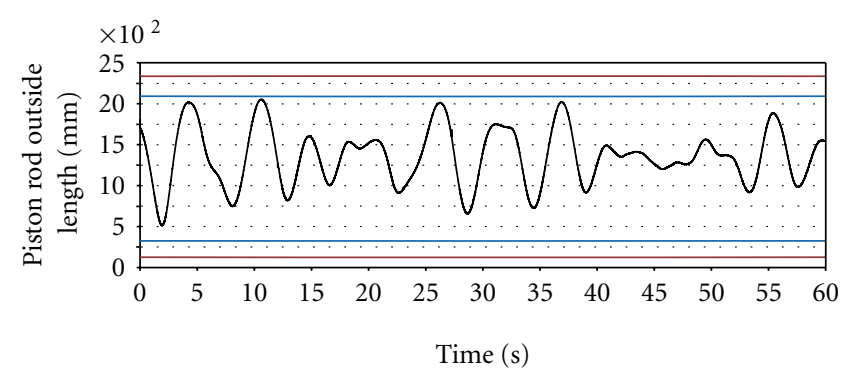

(a)

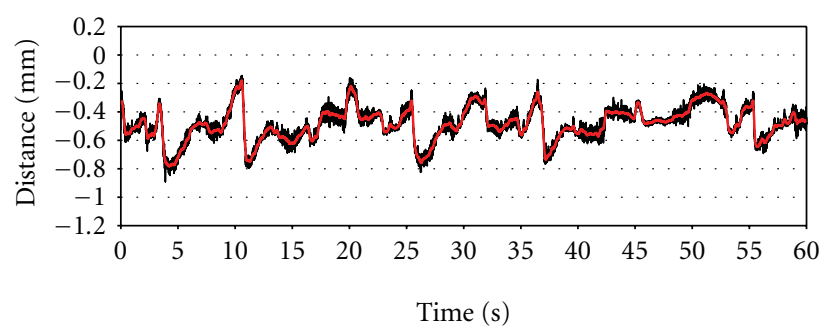

(c)

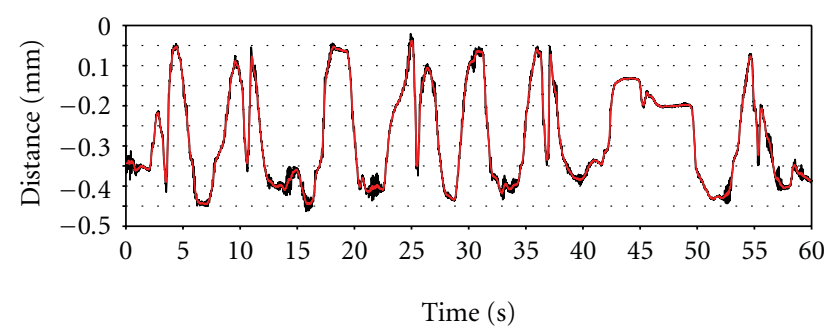

(e)

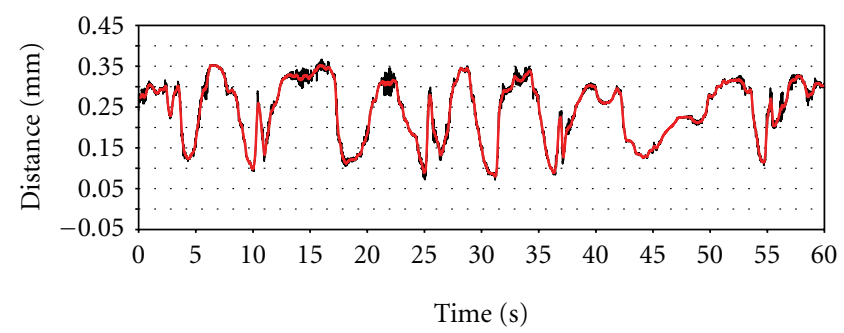

(g)

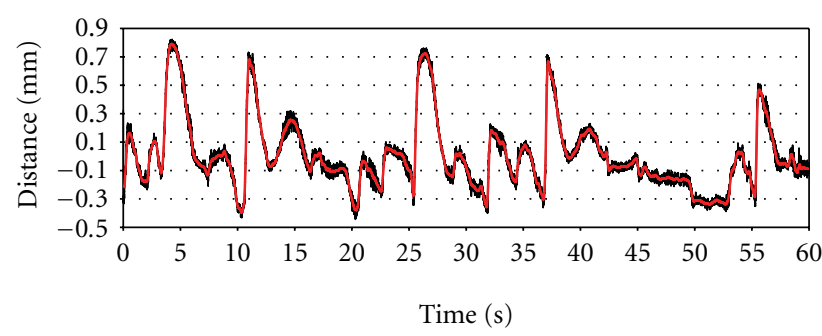

(b)

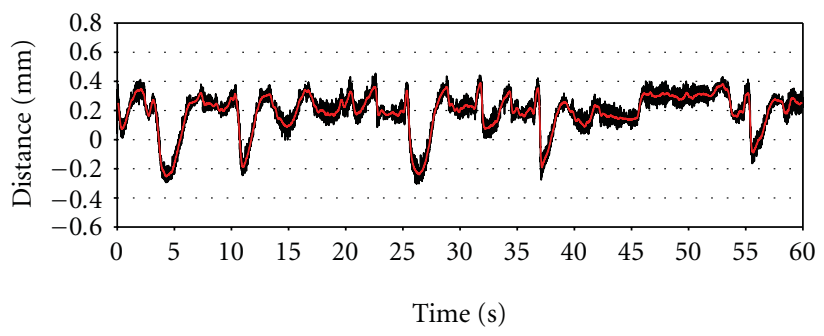

(d)

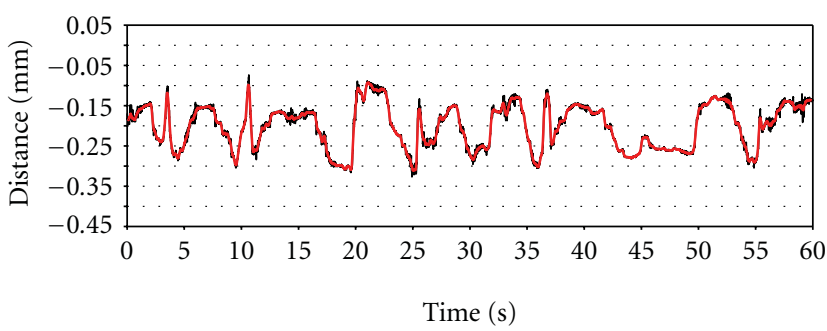

(f)

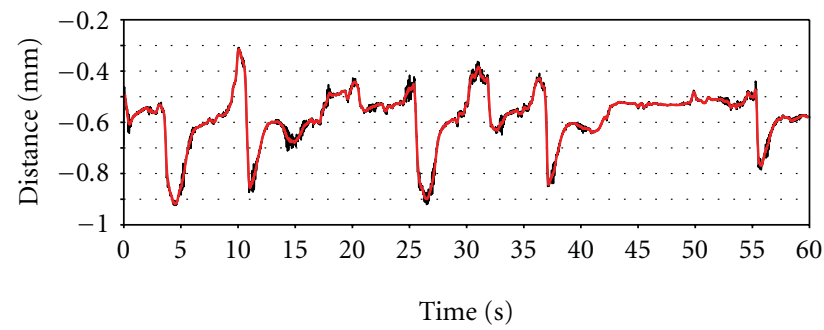

(h)

Figure 22: Sensor output (black) and centered moving averages (red) between 01:02 and 01:03 hours on the 15th of August 2009. (a) Piston rod outside length measured by the draw-wire sensor with free stroke length indicated by two blue lines and maximum stroke length indicated by two brown lines. No moving average required. (b) Distance from middle of measurement range (MMR) towards piston rod surface for PRLS 1. (c) Distance from MMR towards piston rod surface for PRLS 2. (d) Distance from MMR towards piston rod surface for PRLS 3. (e) Distance from MMR towards seal housing surface for SHLS 1. (f) Distance from MMR towards seal housing surface for SHLS 2. (g) Distance from MMR towards seal housing surface for SHLS 3. (h) Distance from MMR towards the bottom surface of the seawater collector, which is attached to the seal housing, for SHLS 4.

peak-to-peak nonlinearity of $<0.015 \%$ of Full Scale Output (FSO), see Figure 23.

The nonlinearity is more or less the same, both in characteristics and magnitude, for all the 7 laser sensors along the measurement range. In the product catalogue the nonlinearity is stated as $<0.08 \%$ of FSO [54]. This is a precaution by the manufacturer and should be viewed as an upper limit. FSO is given as $10 \mathrm{~V}$ or $20 \mathrm{~mm}$. The factory calibration is performed on a flat white ceramic surface in no-noises conditions. Deviations in the target surface roughness, reflectivity, fluctuations in temperature and sensor mounting (tilt) may increase the error, but never above $0.08 \%$ of FSO. Similar accuracy assessments for different target surfaces have be found in literature for a triangulation sensor with a PSD detector [80].

6.1.2. Draw-Wire Sensor. The draw-wire sensor has a specified nonlinearity of $\pm 3 \mathrm{~mm}$ (or $\pm 0.1 \%$ of FSO) [62]. 


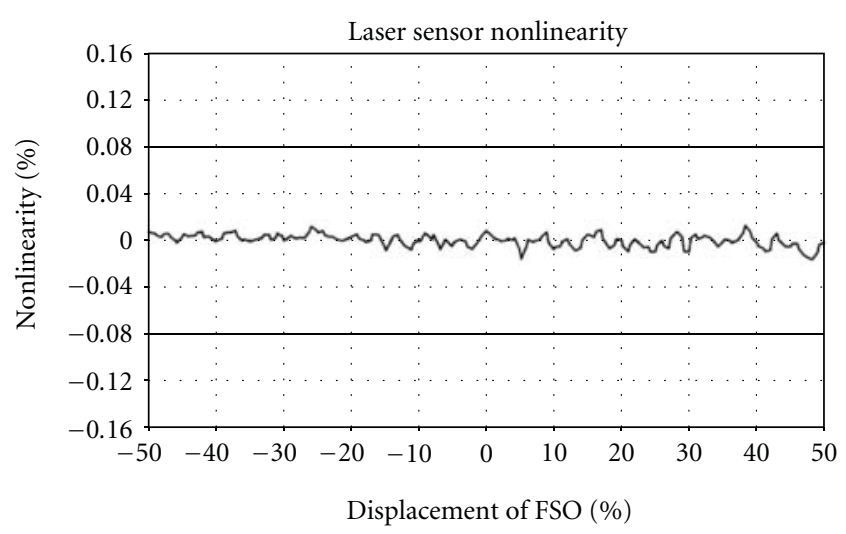

FIGURE 23: Laser sensor nonlinearity from factory calibration.

\subsection{Error due to Temperature Instability}

6.2.1. Laser Sensors. The laser sensors themselves have a temperature instability of $0.01 \%$ of $\mathrm{FSO} /{ }^{\circ} \mathrm{C}$, which mainly consists of a drift in offset. The temperature coefficients for the relevant components in the rest of the data acquisition system are given by Boström et al. [21]. The resistors in the signal resistive damping have a gain temperature coefficient of $75 \mathrm{ppm}$ of $\mathrm{FSO} /{ }^{\circ} \mathrm{C}$. This temperature drift can be omitted because the two resistors in the voltage divider have the same resistance and the same temperature coefficient. The AD622 in-amps have a maximum offset temperature coefficient of $15 \mu \mathrm{V} /{ }^{\circ} \mathrm{C}$ and a gain temperature coefficient of $50 \mathrm{ppm} /{ }^{\circ} \mathrm{C}$. The addition of a gain resistor $\left(R_{g}\right)$ adds a gain temperature drift of $100 \mathrm{ppm} /{ }^{\circ} \mathrm{C}$. Finally, the PAC input module has a gain temperature coefficient of $10.5 \mathrm{ppm}$ of reading $/{ }^{\circ} \mathrm{C}$ and an offset temperature coefficient of $43 \mathrm{ppm}$ of the used range $/{ }^{\circ} \mathrm{C}$. The input range for the PAC is $\pm 10 \mathrm{~V}$. The total temperature drift affects the transfer functions with an offset shift and a gain drift if the measurements are carried out at another temperature than the calibration temperature of $19^{\circ} \mathrm{C}$.

Even though a change in temperature may cause an offset, the offset will not influence the relative displacement measurements. The relative aspect cancels the influence of an offset. Offset would only influence the measurements if the temperature changed quickly during a wave period or, for instance, during the $60 \mathrm{~s}$ measurements in this paper. Fortunately, the temperature at the bottom of the sea changes very slowly with the seasons. So there are no sudden ambient temperature changes fast enough to influence the relative measurement during the individual wave periods. There is neither any heat emitting source nearby the laser sensor which could increase local temperature for such short-time periods. The negligible short-term gradient of the ambient temperature has been verified by temperature measurements in the WEC [21]. See Section 4.3 for further elaboration on the aspect of the ambient temperature within the WEC.

During operation the ambient temperature was measured by an AD590 sensor with an output of $10 \mathrm{mV} /{ }^{\circ} \mathrm{C}[10]$. The output was amplified by a factor of 2 and logged by the same data acquisition system. During the measurements on the 15th of August the ambient temperature inside the WEC was $19.1^{\circ} \mathrm{C}$ and consequently did not affect the measurements at all. On the 28th of May the ambient temperature was $15.3^{\circ} \mathrm{C}$, which is $3.7^{\circ} \mathrm{C}$ lower than during the system calibration. From examining the measurement data from the entire experiment it becomes clear that only about a tenth of the measurement range is utilized, which reduces the magnitude of the gain drift by an order of magnitude. The gain drift affecting the measurements on the 28th of May presented in this paper can thus be approximated to a value below the resolution of the sensor.

In conclusion, temperature will be stabile for every measurement sequence over any wave period. When comparing relative displacement measurements performed at different times of the experiment from May to September, the influence from temperature will be negligible and that is also one of the advantages of measuring relative displacement compared to absolute position.

6.2.2. Draw-Wire Sensor. The draw-wire sensor, on the other hand, measures absolute position which is affected by the temperature offset. The sensor itself has a temperature coefficient of $\pm 0.005 \%$ of $\mathrm{FSO} /{ }^{\circ} \mathrm{C}$. The temperature instability in the data acquisition system, affecting the draw-wire sensor, is the same as for the laser sensors except that the offset actually influences the axial position of the piston rod.

\subsection{Influence of a Tilting Target Surface on Laser Sensor} Accuracy. The error due to influence of a tilting target surface, or surface tangent plane, depends on how the laser spot deforms on the target and how it is reflected from the surface at different tilting angles. The angles between the target surface normal and the incident laser beam, in the $x-, y$-, or $z$-direction, vary all the time with the relative displacement of the measured object. When the measured object centre axis is aligned with the $z$-axis of both the top plate and the sensor set-up rig, the object is vertical and centered in the middle between the sensors. At that position each laser beam is parallel to the normal of the tangent plane of the target surface at the point where the laser spot hits the target surface.

When the measured object starts to move, the angle between the incident laser beam and its corresponding target surface normal changes depending on how the object moves. According to the manufacturer the apparent change (or error) in measured distance due to influence of a tilting target surface is approximately $0.12 \%$ of the measurement range if the angle reaches $5^{\circ}$ to either of the $x$-, $y$-, and $z$-axes; see Figure 24 . At a $15^{\circ}$ angle the error in distance is $0.2 \%$ of the measurement range. Tilt angles of less than $5^{\circ}$ only have a disturbing effect with surfaces which are highly reflecting, especially when scanning structured surfaces [55].

The small relative displacements in the results of this paper suggest angles far below $5^{\circ}$ in all directions and therefore an almost insignificant error due to tilting. If a $1^{\circ}$ tilting would occur due to a sideway motion perpendicular to one of the sensors, "angle 2" would still only reach $2.48^{\circ}$, as presented in the example of Figure 24, according to the mensuration formulas in circle trigonometry [81]. 


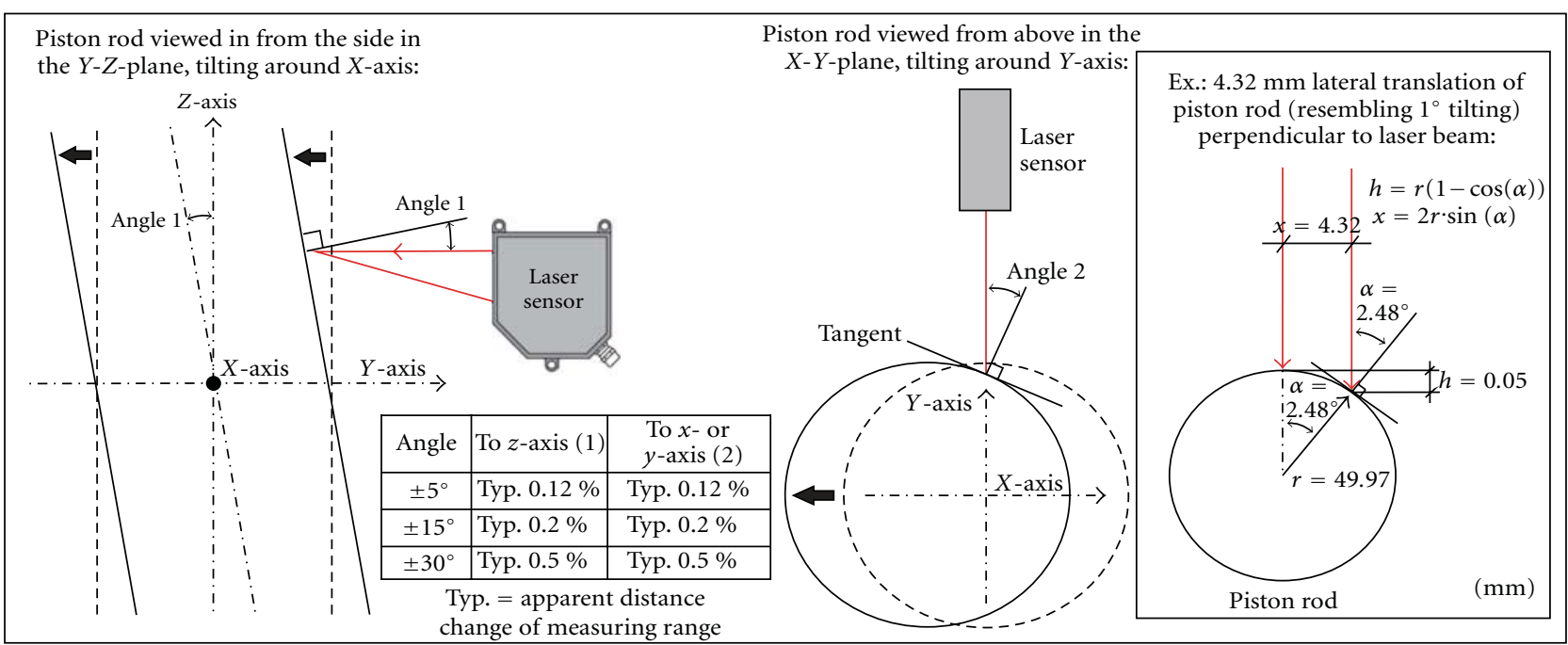

FIGURE 24: Illustration of the influence of a tilting target surface on laser sensor accuracy, when measuring with diffuse reflection.

\subsection{Uncertainties from System Calibration and Misfit of Transfer Functions}

6.4.1. Laser Sensors. The system calibration of the laser sensors takes all errors in the data acquisition system into account except for the effect of temperature drift. Temperature drift leading to offset, on the other hand, does not have an effect on the relative displacement measurements and the gain error is so small that it is negligible, as described in Section 6.2.1. So far the only significant error source is the sensor nonlinearity. The influence of a tilting target surface is ruled out as insignificant for the small tilt angles studied in this case; see Section 6.3. We now look at the statistical uncertainties in the system calibration itself and in the linear regression associated with the curve fitting. We however include some statistical uncertainties which will be introduced as follows.

During system calibration of the laser sensors the PAC voltage output fluctuated on the 2 nd digit, as described in Section 4.7. A mean voltage value $(\bar{y})$ was calculated from 15361 voltage samples $(n=15361)$ for each calibration point $(x, \bar{y})$. The standard error $\left(S_{\bar{y}}\right)$ of the mean voltage is calculated to describe the expected error of the voltage mean $(\bar{y})[73]$.

If we can assume that the same phenomena are generating random errors at every measured distance $(x)$, the standard errors for the calibration points can be "pooled" to express a single estimate of the accuracy of the data acquisition system for each sensor. The pooled unbiased standard error $\left(S P_{\bar{y}}\right)$ is calculated according to $(2)[73,82]$ and given in Table 3:

$$
\begin{aligned}
& S P_{\bar{y}} \\
& \quad=\sqrt{\frac{\left[(n-1) S_{\bar{y} 1}^{2}+(n-1) S_{\bar{y} 2}^{2}+(n-1) S_{\bar{y} 3}^{2}+(n-1) S_{\bar{y} 4}^{2}\right]}{(4 n-4)}} .
\end{aligned}
$$

Another uncertainty affecting the accuracy of the measurements is introduced in the misfit of the transfer function to the calibration points in each graph of Figures 17(a)17(g); see Section 4.7. In order to estimate this misfit the residuals between each mean voltage value $(\bar{y})$, in each calibration point $(x, \bar{y})$, and each predicted voltage value $(\hat{y})$, for the same distance $(x)$ from the transfer function are calculated. A standard error for the residuals is approximated by calculating a root-mean-square error (RMSE) of the residuals, according to (3) [73]. The RMSE-values are given in Table 3:

RMSE

$$
=\sqrt{\frac{\left[\left(\bar{y}_{1}-\hat{y}_{1}\right)^{2}+\left(\bar{y}_{2}-\hat{y}_{2}\right)^{2}+\left(\bar{y}_{3}-\hat{y}_{3}\right)^{2}+\left(\bar{y}_{4}-\hat{y}_{4}\right)^{2}\right]}{(n-2)} .}
$$

Another way of expressing the statistical uncertainty of the curve fitting is to state the coefficients of determination $\left(R^{2}\right.$ coefficients) for the transfer functions. The $R^{2}$-coefficients express how close the estimated values in the transfer functions are to the actual values in the calibration points; see Table 3 .

The generally low standard errors of the mean voltages inform us of very precise mean voltages. In other words, the impact of using weights based on the inverse variances in the linear regression curve fitting would be insignificant. The mean output voltages become very accurate with 6 digits and using them for curve fitting, as described in Section 4.7, results in a very low curve fitting error.

A 95\% confidence interval can also be given for the curve fitting with bounds for the slope and offset coefficients in the transfer functions. The 95\% confidence bounds are defined by a $t$-distribution with 2 degrees of freedom and critical values $t_{0.025}=4.30[83]$. The standard error $\left(S_{\bar{y}}\right)$ of the slope and offset is therefore equal to the bounds in Table 3 divided by 4.30 . Generally the standard offset error may be 
TABLE 3: Compiled statistical data from system calibration and curve fitting for laser sensors.

\begin{tabular}{|c|c|c|c|c|c|c|c|}
\hline Statistics for laser sensors & PRLS 1 & PRLS 2 & PRLS 3 & SHLS 1 & SHLS 2 & SHLS 3 & SHLS 4 \\
\hline \multicolumn{8}{|c|}{ Standard error of the voltage means in each calibration point during system calibration: } \\
\hline$S_{\bar{y} 1}[V]$ & $2.06 E-5$ & $1.45 E-5$ & $9.01 E-6$ & $2.40 E-5$ & $9.21 E-7$ & $6.12 E-6$ & $3.69 E-5$ \\
\hline$S_{\bar{y} 2}[\mathrm{~V}]$ & $9.21 E-7$ & $2.68 E-6$ & $4.03 E-5$ & $9.35 E-6$ & $5.16 E-6$ & $2.36 E-5$ & $2.40 E-5$ \\
\hline$S_{\bar{y} 3}[\mathrm{~V}]$ & $3.78 E-5$ & $1.19 E-5$ & $5.16 E-6$ & $1.13 E-6$ & $9.15 E-6$ & $1.83 E-5$ & $2.16 E-6$ \\
\hline$S_{\bar{y} 4}[\mathrm{~V}]$ & $6.68 E-5$ & $4.89 E-5$ & $5.95 E-5$ & $2.79 E-5$ & $3.41 E-5$ & $1.95 E-6$ & $2.14 E-5$ \\
\hline \multicolumn{8}{|c|}{ Pooled standard error of the mean voltages from system calibration of each sensor: } \\
\hline$S P_{\bar{y}}[\mathrm{~V}]$ & $3.98 E-5$ & $2.62 E-5$ & $3.63 E-5$ & $1.90 E-5$ & $1.78 E-5$ & $1.53 E-5$ & $2.45 E-5$ \\
\hline \multicolumn{8}{|c|}{ Standard error for the voltage residuals from curve fitting of the transfer functions: } \\
\hline RMSE [V] & 0.009400 & 0.010442 & 0.015120 & 0.000644 & 0.001855 & 0.004721 & 0.004169 \\
\hline \multicolumn{8}{|c|}{ Coefficients of determination from curve fitting of the transfer functions: } \\
\hline$R^{2}$ & 0.999998 & 0.999998 & 0.999998 & 1.000000 & 1.000000 & 1.000000 & 1.000000 \\
\hline \multicolumn{8}{|c|}{ 95\% confidence bounds for slope and offset coefficients in the transfer functions: } \\
\hline Slope bounds & \pm 0.0065 & \pm 0.0055 & \pm 0.006 & \pm 0.0005 & \pm 0.0005 & \pm 0.0025 & \pm 0.002 \\
\hline Offset bounds & \pm 0.0215 & \pm 0.02345 & \pm 0.0339 & \pm 0.0016 & \pm 0.0041 & \pm 0.01195 & \pm 0.00945 \\
\hline \multicolumn{8}{|c|}{ Standard error for the slope and offset coefficients in the transfer functions (bounds/4.3): } \\
\hline Std. slope error & \pm 0.0015 & \pm 0.0013 & \pm 0.0014 & \pm 0.00012 & \pm 0.00012 & \pm 0.00058 & \pm 0.00047 \\
\hline Std. offset error & \pm 0.0050 & \pm 0.0055 & \pm 0.0079 & \pm 0.00037 & \pm 0.00095 & \pm 0.0028 & \pm 0.0022 \\
\hline
\end{tabular}

disregarded in relative measurements in the same way as with the temperature drift, described in Section 6.2.1. The standard slope error can however not be disregarded unless its magnitude is very small. In our case, the magnitude will be in parity with or less than the sensor resolution, due to the starting points being very near the sensor midrange and thus close to $0 \mathrm{~V}$, as displayed in Figures 21(b)-21(h) and 22(b)22(h) of Section 5.2 in comparison with Figures 17(a)17(g) of Section 4.7. It is therefore possible to conclude that the standard slope error will have an insignificant impact, especially when dealing with small relative displacements. Table 3 includes the standard offset and slope error from curve fitting.

In conclusion, the pooled standard error of the mean voltages from system calibration is estimated to be insignificant in magnitude; this is also the RMSE of the residuals from curve fitting of the transfer functions.

6.4.2. Draw-Wire Sensor. The most accurate transfer function for the draw-wire sensor was calibrated by measuring the piston rod outside length by hand using a ruler (a scale). The estimated error for the scale is $\pm 1 \mathrm{~mm}$. The draw-wire sensor measuring system was calibrated in two steps, as described in Section 4.8; thus the inaccuracies from the two steps have to be added. The Fluke 187 true RMS multimeter [77] was used for calibrating the part of the measuring system including the draw-wire sensor and the AD622 amplifier circuitry using an accuracy of $\pm(0.03 \%+$ 3d).

The output from the draw-wire sensor is also dependent on the inaccuracy of the digital RMS multimeter Appa 207 [72]. The Appa 207 was used to calibrate the digital Labview amplification in the PAC, as described in Section 4.6. The calibration of the draw-wire sensor, mentioned in Section 4.8, did not include this part; so an inaccuracy of $\pm(0.06 \%+2 \mathrm{~d})$ of the measured value needs to be included for the draw-wire sensor.

Since the chosen transfer function for the draw-wire sensor is based on only two calibration points, curve fitting automatically results in a perfect fit. An uncertainty can therefore not be quantified due to lack of insufficient data. The precision and accuracy of the draw-wire sensor output is not as good as for the laser triangulation sensors. This is not a problem for the experiment since the draw-wire sensor indicates the position of the translator and piston rod over a stroke length of up to $2.210 \mathrm{~m}$. It does not require the same accuracy as when measuring a change in a $0.8 \mathrm{~mm}$ wide clearance gap as in the case between the piston rod and the seal housing.

6.5. Signal-to-Noise Ratio and Uncertainty due to Noise. Signal-to-noise ratio (SNR) is defined as the power ratio between the signal (meaningful information) and the background noise (unwanted signal). The power is represented by the squared ratio of the root-mean-square (RMS) amplitude for the signal $\left(A_{\text {Signal }}\right)$ and the RMS amplitude for the noise $\left(A_{\text {Noise }}\right)$, according to $(4)$ :

$$
\mathrm{SNR}=\frac{P_{\text {Signal }}}{P_{\text {Noise }}}=\left(\frac{A_{\text {Signal }}}{A_{\text {Noise }}}\right)^{2} .
$$

The RMS amplitudes are calculated using (5) with $n=$ 15311. This excludes the first 25 and the last 25 points of the 15361 samples in a minute series due to the chosen interval of 51 samples in the centered moving average:

$$
A=\sqrt{\frac{\left(x_{1}^{2}+x_{2}^{2}+\cdots+x_{n}^{2}\right)}{n}} .
$$

The $x$-values inserted into (5) correspond to $x_{i}^{\text {Noise }}$ when calculating the RMS noise $\left(A_{\text {Noise }}\right)$ and $x_{i}^{\text {Signal }}$ when calculating 
TABLE 4: RMS noise amplitudes and SNR from the results in Figures 21(a)-21(h) and Figures 22(a)-22(h).

\begin{tabular}{lcccccccc}
\hline Noise analysis & $\begin{array}{c}\text { Draw-wire } \\
\text { sensor }\end{array}$ & PRLS 1 & PRLS 2 & PRLS 3 & SHLS 1 & SHLS 2 & SHLS 3 & SHLS 4 \\
\hline 28th May, between 14:10 and 14:11 hours & & & & & & & & \\
RMS noise: & & & & & & & & \\
$\quad$ Distance (mm) & 132.643 & 0.0446 & 0.0435 & 0.0760 & 0.0051 & 0.0031 & 0.0043 & 0.0049 \\
$\quad$ Voltage (V) & 0.4180 & 0.0318 & 0.0311 & 0.0542 & 0.0036 & 0.0022 & 0.0031 & 0.0035 \\
SNR: & 4.87 & 0.42 & 0.40 & 0.34 & 5.38 & 5.77 & 6.70 & 8.15 \\
\hline 15th August, between 01:02 and 01:03 hours & & & & & & & \\
RMS noise: & & & & & & & & \\
$\quad$ Distance (mm) & 2.804 & 0.0261 & 0.0237 & 0.0287 & 0.0087 & 0.0062 & 0.0073 & 0.0101 \\
$\quad$ Voltage (V) & 0.0088 & 0.0365 & 0.0333 & 0.0403 & 0.0122 & 0.0087 & 0.0103 & 0.0142 \\
SNR: & 14708.0 & 86.87 & 23.35 & 21.89 & 188.56 & 74.68 & 101.50 & 103.31 \\
\hline
\end{tabular}

the RMS signal $\left(A_{\text {Signal }}\right)$, according to $(6)$, with $i=1$ to 15311:

$$
\begin{gathered}
x_{i}^{\text {Noise }}=x_{i}^{\text {Distance output sample }}-x_{i}^{\text {Centered moving average }}, \\
x_{i}^{\text {Signal }}=x_{i}^{\text {Centered moving average }}-\bar{x}_{\text {mean }}^{\text {Centered moving average }} .
\end{gathered}
$$

The calculated SNR for the draw-wire sensor and the 7 laser triangulation sensors in the result plots of Figures 21(a) $-21(\mathrm{~h})$ and $22(\mathrm{a})-22(\mathrm{~h})$ is presented in Table 4 . Table 4 presents the RMS noise in both voltage and distance. The RMS noise in distance is calculated by including the transfer functions. The RMS noise voltages, on the other hand, are not influenced by the transfer functions. In both cases the RMS noise can be seen as the difference between the sensor output (black) and the centered moving averages (red) in Figures 21(a)-21(h) and 22(a)-22(h). The RMS noise voltages are calculated in relation to centered moving averages with a window of 51 voltage values. Voltage noise is a more general representation of noise and enables a more accurate comparison between sensors.

In mid-June the underwater substation was lifted up for adjustments and repairs. It was reinstalled a couple of weeks later. During this repair time the WECs were in uninterrupted operation, but switched to resistive underwater dump loads. Measurement data could not be logged during this time, since the underwater substation is required in order to $\mathrm{A} / \mathrm{D}$-convert and relay the data to shore.

When the sea cables from the WECs were reconnected to the underwater substation at the LRS, the RMS noise amplitude for the draw-wire sensor decreased by a factor of 50, resulting in a hugely increased SNR. The reason for the reduction in noise is unknown. It could perhaps be attributed to the correction of a faulty ground of a shielded cable in the substation as it was reassembled on shore. The WEC was operating in the same sea state during the presented measurements for May and August; so the operating conditions and external influences were more or less the same with regard to noise.

The RMS noise amplitudes for the laser sensors were approximately the same in May and August, indicating that the possible faulty grounding only affected the drawwire sensor. In May the RMS noise for PRLS 1-3 was approximately 10 times higher than the RMS noise for SHLS 1-4. In August this ratio was reduced to 3 times as high, due to increased noise in the output from SHLS 1-4. Possibly a loose part of the SHLS-cables might have moved slightly and altered the electromagnetic impact on the noise in the output. Another reason for the changes in RMS noise can be the influence of speckle, which is dependent on the specific target surface area currently reflecting the laser beam.

Speckle can be estimated through experiments by comparing with known reference surfaces. However, such an investigation post experiment would not be so reliable since the target surface of the piston rod is subjected to successive wear and might change slightly over time. A general characterization of the noise will however be performed in future work.

One of the most interesting aspects in Table 3 is the fact that the SNR for all laser sensors was considerably higher in August compared to May, especially for PRLS 1-3. This is also the case for SHLS 1-4, even though the RMS noise was 4 times higher in August. The reason for this is the increased oscillating signal, which is owed to the actual increased relative displacement of the measured objects. Both the piston rod and the seal housing produced higher signal amplitudes in August. The increased relative displacement can be attributed to the mechanical wear between both the funnel and the buoy line and between the piston rod and the dynamic sealing system inside the seal housing.

\section{Discussion}

This paper describes a measurement system designed to measure relative displacement of a piston rod mechanical leadthrough transmission inside WEC prototype L2 at the LRS. Increased knowledge about the performance of the piston rod mechanical lead-through transmission is important to the development of the emerging WEC technology. It may also bring some valuable input to other marine vessels or devices in need of a sealed linear mechanical transmission affected by side forces and tilting displacements. Measuring the relative displacement in-situ of the piston rod and seal housing and the change in clearance gap gives valuable information about the successive wear, the sustainability and 
life time for guide elements and sealing components, and the requirements for further development.

This paper describes the geometrical set-up of the sensors and all relevant steps in the creation of the entire measurement system. Measuring relative displacement rather than absolute position reduces the unknowns and simplifies the measurements for future work, for example, in describing the relative displacements in 3D. The aim of describing the motion in 3D is the reason for the number of sensors and their relative positions. An in-depth theoretical model of operation for the transmission has been given in the paper. The mode of operation for the transmission is described as pure tilting around a centre of rotation at the level of the capsule top plate. Some translation may occur but will be very small in magnitude due to the design of the mechanics. Future work will determine how small that translation might be if there is one.

The procedure of system calibration has been explained and a thorough error and uncertainty investigation followed to describe the accuracy of the measurements, along with an analysis of the signal-to-noise ratio in relation to filtered signals using centered moving averages. Future comparisons can be made with measurements performed at different moments in time with different, or similar, circumstantial parameters. Correlations can also be made with data from other sensors in the WEC, such as possible leakage data with possible conclusions drawn on the consequence of wear. Understanding the relative displacement of each object also gives valuable information about the performance of the inherent parts in the direct drive as a whole that explains recognized specific behaviors in the measurement of other parts in the WEC.

The results in this paper are presented as relative displacements, or sideway movements, for the laser sensors at the sensor level during two different experimental periods, 2.5 months apart. It is possible to see a clear correlation in the results between the axial displacement of the piston rod due to the pull of the ocean waves and the relative displacements of the target surfaces of the measured objects. The seal housing follows the motion of the piston rod but may with time be subjected to deviations due to wear of the guide elements and other phenomena relating to the sliding of the piston rod and compression of the rubber gasket.

The relative displacements have the same periods and peaks at the same moments in time all along the measurement period and move in congruence with the axial piston rod motion, as measured by the draw-wire sensor. The sinusoidal curves and the peaks are very distinguishable, especially in the August measurements. The seal housing periodicity in May is a little bit harder to distinguish, due to the small amplitudes in combination with the specific behavior that occurs at the peak in all SHLS plots. The peak corresponds to the axial turning-points, that is, when the translator stops and starts to move in the other direction. However, at that specific point there is sudden sharp change in motion appearing in the opposite direction of the general movement. The phenomena are especially distinguishable in the output from SHLS 1 in Figure 21(e) (May) after $31 \mathrm{~s}$ and in most of the peaks in Figure 22(e) (August), for instance, after $11 \mathrm{~s}$. This sudden change is also apparent in the other SHLS plots, but not in the piston rod displacements measured by the PRLS.

Speculations made about the reason for this behavior may include some kind of stick slip behavior between the guide elements and the piston rod or a reaction force from the rubber gasket being released at the turning-point. It might also depend on sudden translation due to the influence of the double-hinged link. A lateral translation at the turning point would correspond to a relative displacement change in the opposite direction compared to that of tilting. Further work needs to be done in order to investigate what this sudden change in motion might depend upon and what it signifies.

The results presented in this paper describe operation within the so-called free stroke length, without the translator hitting the end stops or even the end stop compression springs, which constitutes a specific case with other consideration outside of the scope of this paper. So far it is clear to see in the results that the measured objects move together. There is a clear congruence in the periods and amplitudes of the relative displacements. The motion is pulsating from a starting point to a maximum relative displacement and then back again to the starting point if allowed by the motion of the ocean waves. The exception is the sudden change in displacement at the peaks, as mentioned above.

Sometimes a large wave is followed by a small wave which will result in corresponding smaller measured relative displacements across-the-board. Generally, the longer the piston rod outside length becomes, the larger is the relative displacement response in the laser sensor output. This is due to the larger forces acting on the system. It is apparent that longer strokes result in larger tilt angles corresponding to an increase in sensor amplitude. The magnitude and sign of the relative displacements, as measured by the individual laser sensors, indicate in which direction the tilting is occurring.

For SHLS 4, which measures on the seal housing in the $z$ axis direction, this has a specific meaning. If the tilting occurs in the azimuth angle corresponding to a lateral bearing of $113.8^{\circ}$, that is, towards SHLS 4, the output magnitude will be high for that sensor. On the other hand, if the tilting occurs in an azimuth angle perpendicular to that direction, the sensor output from SHLS 4 will be minimal. In such a way it is not only an instrument for establishing the $z$-axis motion of the seal housing on the rubber gasket, but also an instrument of verifying the direction of tilting in correlation with the other SHLSs.

\section{Conclusion}

A set-up of 7 laser triangulation sensors and a draw-wire sensor inside an offshore WEC on the ocean floor has be successfully implemented for measuring the cyclical relative displacement of a piston rod mechanical lead-through transmission in the direct drive. The measurement signals from the rigidly mounted sensors have been successfully transmitted to shore through a robust data acquisition system and maintained for the duration of the entire 4.5month experiment with very good reliability, precision, and 
accuracy. The results show the capability of continuous precise and accurate long-term relative displacement measurements in common mode of two measured objects in relative motion inside an offshore WEC on the ocean floor.

Results are presented from two $60 \mathrm{~s}$ measurement periods with approximately 2.5 -month separation. From studying the results it is possible to draw the conclusion that the two measured objects, that is, the piston rod and the seal housing, move more or less together in a plausible and predicted way with regard to the theoretical model. It is also possible to conclude that the sensor set-up and measuring system performs in the intended way. These conclusions enable further analysis and evaluation of the motion of the piston rod mechanical lead-through transmission in accordance with the described theoretical model and with the use of the displacement measurement data from the experiment.

\section{Acknowledgments}

This paper is the product of research carried out within the Lysekil project. The authors are affiliated with the Swedish Centre for Renewable Electric Energy Conversion at Uppsala University in Uppsala, Sweden. The research is supported by The Swedish Energy Agency, VINNOVA, Statkraft AS, Vattenfall AB, Fortum OY, Falkenberg Energy AB, Helukabel, Draka Cable AB, Pro Enviro, Seabased AB, The Gothenburg Energy Research Foundation, The Göran Gustavsson Research Foundation, Ångpanneföreningen's Foundation for Research and Development, the Olle Engkvist Foundation, The J. Gust. Richert Foundation, CF Environmental Fund, Vargöns Research Foundation, the Swedish Research Council Grant no. 621-2009-3417, and the Wallenius Foundation.

\section{References}

[1] J. Falnes, "A review of wave-energy extraction," Marine Structures, vol. 20, no. 4, pp. 185-201, 2007.

[2] B. Drew, A. R. Plummer, and M. N. Sahinkaya, "A review of wave energy converter technology," Proceedings of the Institution of Mechanical Engineers, Part A, vol. 223, no. 8, pp. 887-902, 2009.

[3] A. F. D. O. Falcão, "Wave energy utilization: a review of the technologies," Renewable and Sustainable Energy Reviews, vol. 14, no. 3, pp. 899-918, 2010.

[4] J. P. Kofoed, P. Frigaard, E. Friis-Madsen, and H. C. Sørensen, "Prototype testing of the wave energy converter wave dragon," Renewable Energy, vol. 31, no. 2, pp. 181-189, 2006.

[5] R. Henderson, "Design, simulation, and testing of a novel hydraulic power take-off system for the Pelamis wave energy converter," Renewable Energy, vol. 31, no. 2, pp. 271-283, 2006.

[6] D. Elwood, S. C. Yim, J. Prudell et al., "Design, construction, and ocean testing of a taut-moored dual-body wave energy converter with a linear generator power take-off," Renewable Energy, vol. 35, no. 2, pp. 348-354, 2010.

[7] M. Leijon, H. Bernhoff, M. Berg, and O. Ågren, "Economical considerations of renewable electric energy productionespecially development of wave energy," Renewable Energy, vol. 28, no. 8, pp. 1201-1209, 2003.

[8] M. Leijon, O. Danielsson, M. Eriksson et al., "An electrical approach to wave energy conversion," Renewable Energy, vol. 31, no. 9, pp. 1309-1319, 2006.
[9] M. Leijon, C. Boström, O. Danielsson et al., "Wave energy from the north sea: experiences from the lysekil research site," Surveys in Geophysics, vol. 29, no. 3, pp. 221-240, 2008.

[10] O. Svensson, E. Strömstedt, A. Savin, and M. Leijon, "Sensors and measurements inside the second and third wave energy converter at the lysekil research site," in Proceedings of the 9th European Wave and Tidal Energy Conference, Southampton, UK, 2011.

[11] O. Langhamer, D. Wilhelmsson, and J. Engström, "Artificial reef effect and fouling impacts on offshore wave power foundations and buoys - a pilot study," Estuarine, Coastal and Shelf Science, vol. 82, no. 3, pp. 426-432, 2009.

[12] S. Gustafsson, Measuring of waves at Islandsberg and literature survey of wave measurement technology, M.S. thesis, Division for Electricity and Lightning Research, UPTEC F04048, Uppsala University, 2004.

[13] S. Tyrberg, H. Gravrakmo, and M. Leijon, "Tracking a wave power buoy using a network camera-system analysis and first results," in Proceedings of the 28th International Conference on Ocean, Offshore and Arctic Engineering (OMAE '09), Honolulu, Hawaii, USA, 2009.

[14] J. Cruz, R. Sykes, P. Siddorn, and R. E. Taylor, "Estimating the loads and energy yield of arrays of wave energy converters under realistic seas," IET Renewable Power Generation, vol. 4, no. 6, pp. 488-497, 2010.

[15] P. Ricci, J. B. Saulnier, and A. Falcao, "Point-absorber arrays: a configuration study off the Portuguese West-Coast," in Proceedings of the 7th European Wave and Tidal Energy Conference (EWTEC '07), Porto, Portugal, 2007.

[16] M. Rahm, C. Boström, O. Svensson, M. Grabbe, F. Bülow, and M. Leijon, "Offshore underwater substation for wave energy converter arrays," IET Renewable Power Generation, vol. 4, no. 6, pp. 602-612, 2010.

[17] C. Boström, O. Svensson, M. Rahm et al., "Design proposal of electrical system for linear generator wave power plants," in Proceedings of the 35th Annual Conference of the IEEE Industrial Electronics Society (IECON '09), pp. 4393-4398, November 2009.

[18] C. Boström, E. Lejerskog, M. Stålberg, K. Thorburn, and M. Leijon, "Experimental results of rectification and filtration from an offshore wave energy system," Renewable Energy, vol. 34, no. 5, pp. 1381-1387, 2009.

[19] C. Boström and M. Leijon, "Operation analysis of a wave energy converter under different load conditions," IET Renewable Power Generation, vol. 5, no. 3, pp. 245-250, 2011.

[20] O. Svensson, C. Boström, M. Rahm, and M. Leijon, "Description of the control and measurement system used in the low voltage marine substation at the Lysekil research site," in Proceedings of the 8th European Wave and Tidel Energy Conference (EWTEC '09), pp. 44-50, Uppsala, Sweden, 2009.

[21] C. Boström, M. Rahm, and O. Svensson, "Temperature measurements in a linear generator and marine substation for wave power," in Proceedings of the 29th International Conference on Ocean, Offshore and Arctic Engineering (OMAE '10), p. 8, Shanghai, China, 2010.

[22] M. Leijon, R. Waters, and M. Rahm, "Catch the wave to electricity," IEEE Power and Energy Magazine, vol. 7, no. 1, pp. 50-54, 2009.

[23] O. Danielsson, M. Eriksson, and M. Leijon, "Study of a longitudinal flux permanent magnet linear generator for wave energy converters," International Journal of Energy Research, vol. 30, no. 14, pp. 1130-1145, 2006. 
[24] O. Danielsson and M. Leijon, "Flux distribution in linear permanent-magnet synchronous machines including longitudinal end effects," IEEE Transactions on Magnetics, vol. 43, no. 7, pp. 3197-3201, 2007.

[25] O. Langhamer and D. Wilhelmsson, "Colonisation of fish and crabs of wave energy foundations and the effects of manufactured holes-a field experiment," Marine Environmental Research, vol. 68, no. 4, pp. 151-157, 2009.

[26] R. Waters, J. Engström, J. Isberg, and M. Leijon, "Wave climate off the Swedish west coast," Renewable Energy, vol. 34, no. 6, pp. 1600-1606, 2009.

[27] S. H. Salter, J. R. M. Taylor, and N. J. Caldwell, "Power conversion mechanisms for wave energy," Proceedings of the Institution of Mechanical Engineers, Part M, vol. 216, pp. 1-27, 2002.

[28] A. Savin, O. Svensson, E. Strömstedt, C. Boström, and M. Leijon, "Determining the service life of a steel wire under a working load in the Wave Energy Converter (WEC)," in Proceedings of the 28th International Conference on Ocean, Offshore and Arctic Engineering (OMAE '09), pp. 839-844, June 2009.

[29] J. S Wilson, Ed., Sensor Technology Handbook, Newnes/ Elsevier, 2005.

[30] J. Fraden, Handbook of Modern Sensors-Physics, Designs and Applications, Springer, New York, NY, USA, 3rd edition, 2004.

[31] D. S. Nyce, Linear Position Sensors-Theory and Application, John Wiley \& Sons, 2004.

[32] R. A. Jarvis, "Perspective on range finding techniques for computer vision," IEEE Transactions on Pattern Analysis and Machine Intelligence, vol. 5, no. 2, pp. 122-139, 1983.

[33] J. L. C. Sanz, Advances in machine vision, Springer, New York, NY, USA, 1989.

[34] K. Meyer, H. L. Applewhite, and F. A. Biocca, "A survey of position trackers," Presence, vol. 1, no. 2, pp. 173-200, 1992.

[35] B. L. Curless, New methods for surface reconstruction from range images, Ph.D. thesis Dissertation, Electrical Engineering, Stanford University, 1997.

[36] P. K. Rastogi, Optical Measurement Techniques and Applications, Artech House, London, UK, 1997.

[37] "Electro-optical sensors for mechanical applications," in Optical Sensors and Microsystems : New Concepts, Materials, Technologies, F. Docchio, M. Bonardi, S. Lazzari, R. Rodella, and E. Zorzella, Eds., vol. 2, pp. 275-289, Kluwer Academic /Plenum Publishers, New York, NY, USA, 2000.

[38] F. Chen, G. M. Brown, and M. Song, "Overview of threedimensional shape measurement using optical methods," Optical Engineering, vol. 39, no. 1, pp. 10-22, 2000.

[39] F. Blais, "Review of 20 years of range sensor development," Journal of Electronic Imaging, vol. 13, no. 1, pp. 231-243, 2004.

[40] J. J. Orteu, "3-D computer vision in experimental mechanics," Optics and Lasers in Engineering, vol. 47, no. 3-4, pp. 282-291, 2009.

[41] Y. Jiang, Q. Zixue, W. Shufang, and S. Jianxin, "Research on wide range measurement system of free-form surfaces using laser displacement detector and grating displacement sensor," in Proceedings of the 9th International Conference on Electronic Measurement and Instruments (ICEMI '09), pp. 21011-21014, August 2009.

[42] S. Kanai, Y. Hatsukade, K. Hayashi, K. Mori, and S. Tanaka, "Eddy-current-based SQUID-NDE system for copper tubes with laser displacement sensor," IEEE Transactions on Applied Superconductivity, vol. 19, no. 3, Article ID 5153055, pp. 786790, 2009.
[43] Y. Sato and M. Otsuki, "Three-dimensional shape reconstruction by active rangefinder," in Proceedings of the IEEE Computer Society Conference on Computer Vision and Pattern Recognition (CVPR '93), pp. 142-147, June 1993.

[44] P. Palojärvi, K. Määttä, and J. Kostamovaara, "Integrated timeof-flight laser radar," IEEE Transactions on Instrumentation and Measurement, vol. 46, no. 4, pp. 996-999, 1997.

[45] S. Zivanovic, J. Elazar, and M. Tomic, "Fiber-optic displacement sensor," in Proceedings of the 21st International Conference on Microelectronics (MIEL '97), pp. 561-564, September 1997.

[46] D. Acosta, O. García, and J. Aponte, "Laser triangulation for shape acquisition in a 3D scanner plus scanner," in Proceedings of the Electronics, Robotics and Automotive Mechanics Conference (CERMA '06), pp. 14-19, September 2006.

[47] M. Demeyere and C. Eugène, "Measurement of cylindrical objects by laser telemetry: a generalization to a randomly tilted cylinder," IEEE Transactions on Instrumentation and Measurement, vol. 53, no. 2, pp. 566-570, 2004.

[48] X. M. Wu, N. X. Zhang, T. L. Ren, and L. T. Liu, "Nondestructive evaluation of MEMS devices by laser confocal measurements," in Proceedings of the International Conference on MEMS, NANO and Smart Systems (ICMENS '05), pp. 6973, July 2006.

[49] W. Osten, "Application of optical shape measurement for the nondestructive evaluation of complex objects," Optical Engineering, vol. 39, no. 1, pp. 232-243, 2000.

[50] S. Roose, Y. Stockman, P. Rochus et al., "Optical methods for non-contact measurements of membranes," Acta Astronautica, vol. 65, no. 9-10, pp. 1317-1329, 2009.

[51] H. V. Christensen, "Retrieval of 3D-position of a passive object using infrared led's and photodiodes," in Proceedings of the IEEE International Conference on Acoustics, Speech, and Signal Processing (ICASSP '05), vol. 4, pp. IV1093-IV1096, March 2005.

[52] W. W. Zhang and B. H. Zhuang, "Non-contact laser inspection for the inner wall surface of a pipe," Measurement Science and Technology, vol. 9, no. 9, pp. 1380-1387, 1998.

[53] B. Embleton and S. Axelrod, "On-line product quality measurements for continuous sheet processes," in Proceedings of the Annual Technical Conference of the Society of Plastics Engineers (ANTEC'00), pp. 357-361, Orlando, Fla, USA, 2000.

[54] Micro-Epsilon, "Product catalogue for optoNCDT laser sensors," Modifications reserved/Y9761188-D091120DGO, 2010, http://www.micro-epsilon.com/download/products/cat-opto NCDT-en.pdf.

[55] Micro-Epsilon, "Instruction manual, optoNCDT 1700," version X9751139-C151100HDR, 2010, http://www.microepsilon.com/download/manuals/man-optoNCDT-1700-en .pdf.

[56] Z. Ji and M. C. Leu, "Design of optical triangulation devices," Optics and Laser Technology, vol. 21, no. 5, pp. 339-341, 1989.

[57] R. Baribeau and M. Rioux, "Influence of speckle on laser range finders," Applied Optics, vol. 30, pp. 2873-2878, 1991.

[58] M. Buzinski, A. Levine, and W. H. Stevenson, "Laser triangulation range sensors: a study of performance limitations," Journal of Laser Applications, vol. 4, pp. 29-36, 1992.

[59] J. Feng, Q. Feng, and C. Kuang, "Status of laser displacement measurement techniques based on triangulation," in Proceedings of the 5th Internatinal Symposium on Test and Measurement (ISTM '03), pp. 3658-3661, June 2003.

[60] S. Lindroth and M. Leijon, "Offshore wave power measurements-a review," Renewable and Sustainable Energy Reviews, vol. 15, no. 9, pp. 4274-4285, 2011. 
[61] Micro-Epsilon, "Product catalogue for draw-wire sensors," Modifications reserved/Y9761111-F021110DGO, 2010, http:// www.micro-epsilon.com/download/products/cat-wire SENSOR-en.pdf.

[62] Micro-Epsilon, "Instruction manual, wireSENSOR WDS," version X975X034-D031090HDR, 2010, http://www.microepsilon.com/download/manuals/man-wireSENSOR-P60-P96 -P115-de-en.pdf.

[63] N. Vukašinovíc, D. Bračun, J. Možina, and J. Duhovnik, "The influence of incident angle, object colour and distance on CNC laser scanning," International Journal of Advanced Manufacturing Technology, vol. 50, no. 1-4, pp. 265-274, 2010.

[64] B. Curless and M. Levoy, "Better optical triangulation through spacetime analysis," in Proceedings of the 5th International Conference on Computer Vision, pp. 987-994, June 1995.

[65] Mitutoyo, "Surftest SJ-400, Portable Surface Roughness Tester," Catalog no. E4185-178.

[66] Mitutoyo, "SJ-400 Surface Roughness Tester, User's manual," No. 99MBB093A4, series no. 178.

[67] A. Roos, C. G. Ribbing, and B. Karlsson, "Stainless steel solar mirrors-a material feasibility study," Solar Energy Materials, vol. 18 , no. 5, pp. 233-240, 1989.

[68] D. Welch, "Thickness measurement using laser triangulation," Sensors magazine, 2010, http://www.sensorsmag.com/sensors/motion-velocity-displacement/thickness-measurementsusing-laser-triangulation-7050.

[69] Henkel KGaA, "Loctite-Threadlocking Capability Guide," 2008, http://www.loctite.co.uk/uke/content_data/LOCT.C.G .final_english_version_genn_08.pdf.

[70] Nord-Lock Group, "Nord-Lock washers, product information," version 70025EN, 2011, http://www.nord-lock.com/ upload/files/320/70025EN-Washers-brochure_201104.pdf.

[71] Analog Devices, "Low cost instrumentation amplifier, AD 622," version C00777-0-8/07(D), 2007, http://www.analog .com/static/imported-files/data_sheets/AD622.pdf.

[72] Appa Technology Corporation, "APPA 200 Series VersaM-eter-technical specifications," 2002, http://www.appatech.com/upload/product/techdata11350598914707.pdf.

[73] G. P. Quinn and M. J. Keough, Experimental Design and Data Analysis for Biologists, Cambridge University Press, Cambridge, UK, 2007.

[74] Z. Qian, Y. Fan, and Z. Lu, "Application of draw-wire displacement sensors on structural health monitoring of Jiangyin bridge," in Proceedings of the SPIE-International Society for Optical Engineering, March 2006.

[75] J. W. Youn, K. S. Yoon, and D. Y. Lee, "Three-dimensional measurement system for pipe assembly process," Measurement Science and Technology, vol. 16, no. 10, pp. 2091-2100, 2005.

[76] Micro-Epsilon, "More precision, wireSENSOR applications," 2010, http://www.micro-epsilon.com/download/products/ cat-wireSENSOR-Application-Guide-en.pdf.

[77] Fluke Corporation, "Fluke 187 \& 189 True RMS Multimeteruser manual," Rev. 2, 6/02 ed, 2000, http://assets.fluke.com/ manuals/187_189_umeng0200.pdf.

[78] Teo Teknikk AS, "5 ton Crane scale-technical specification," 2011, http://www.teo.no/index.php/eng/Venstremeny/Products/Crane-Scales.

[79] S. W. Smith, The Scientist and Engineer's Guide to Digital Signal Processing, Technical Publishing, San Diego, Calif, USA, 2nd edition, 1999.

[80] F. Murakami, "Accuracy assessment of a laser triangulation sensor," in Proceedings of the 10th Anniversary IMTC94 Advanced Technologies in I M 1994 IEEE Instrumentation and Measurement Technolgy Conference, vol. 2, pp. 802-805, 1994.
[81] L. Råde and B. Westergren, Mathematics Handbook for Science and Engineering, Springer, New York, NY, USA, 2004.

[82] M. R. Spiegel, J. Schiller, and R. A. Srinivasan, Schaum's Outlines-Probability and Statistics, McGraw-Hill, New York, NY, USA, 3rd edition, 2009.

[83] L. Olbjer, Experimentell Och Industriell Statistik (Swedish), Department of Mathematical Statistics, University of Lund and Lund Institute of Technology, 1st edition, 1988. 

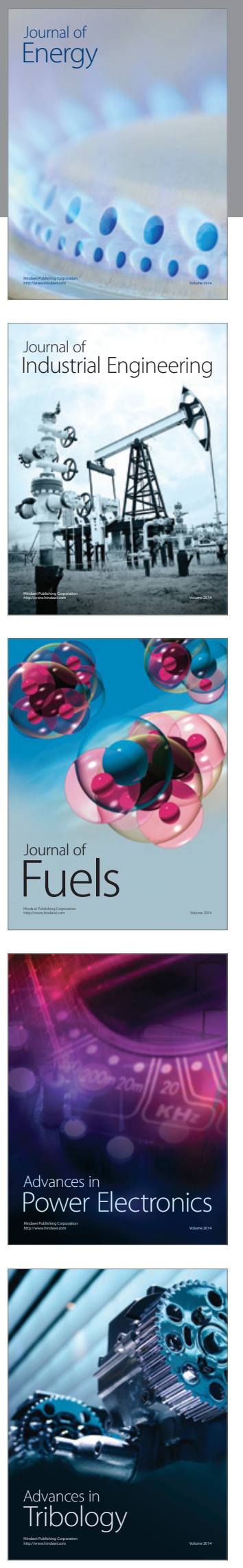
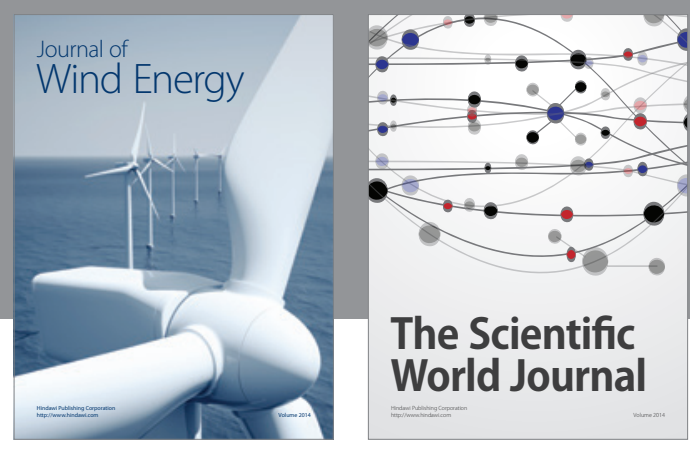

The Scientific World Journal

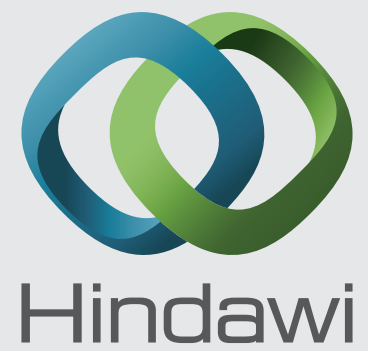

Submit your manuscripts at http://www.hindawi.com
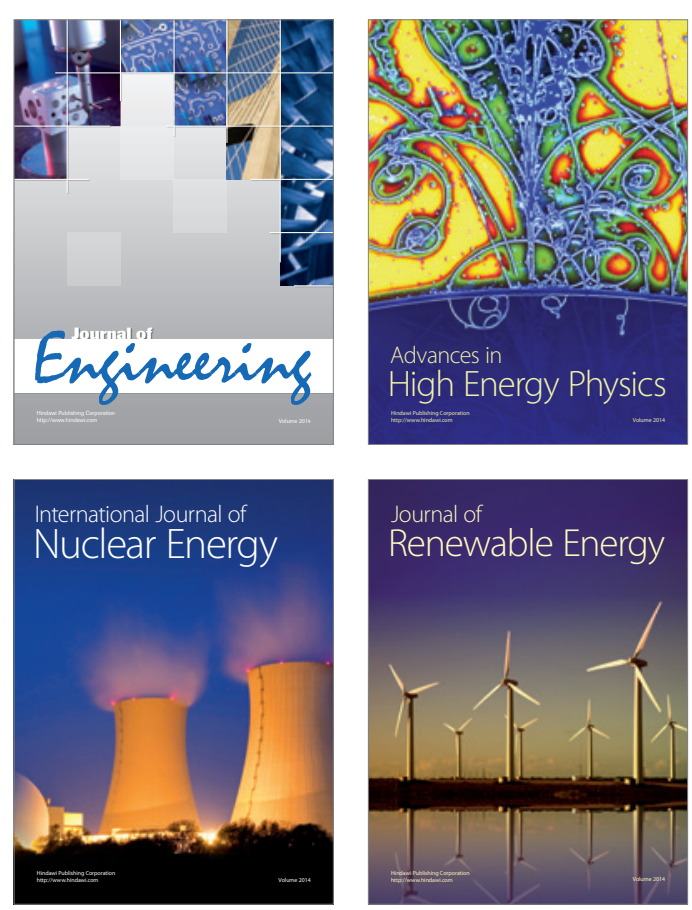

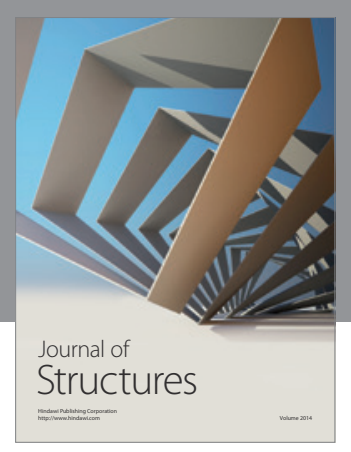

Rotating
Mechinery
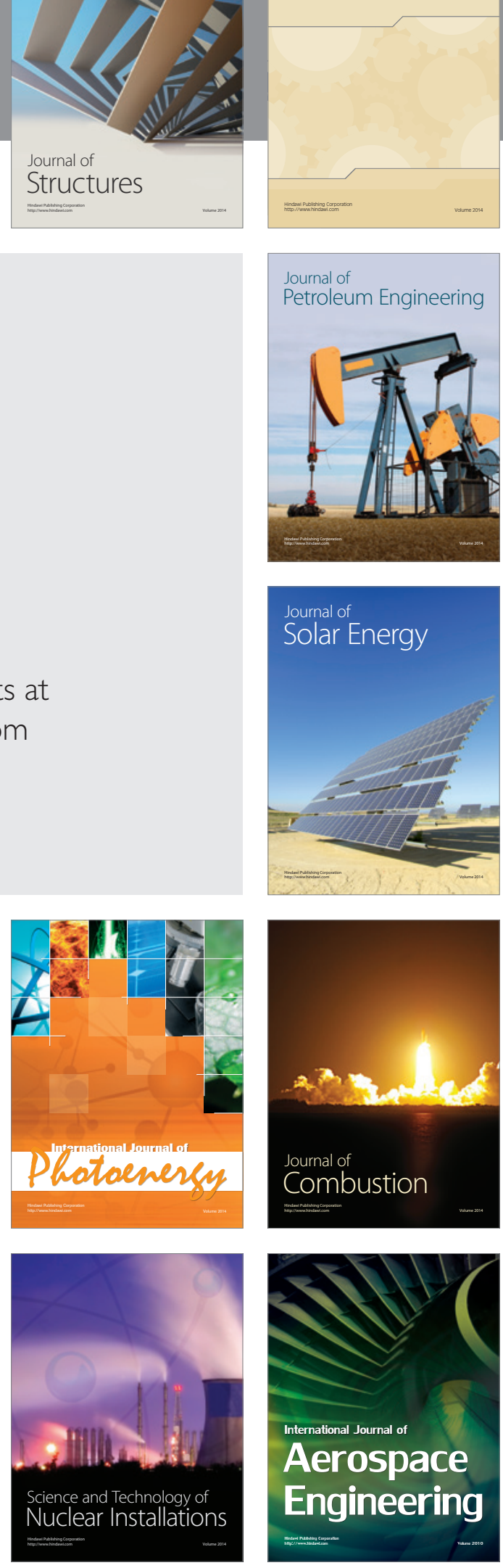